\title{
The Contribution of Individual Exercise Training Components to Clinical Outcomes in Randomised Controlled Trials of Cardiac Rehabilitation: A Systematic Review and Meta-regression
}

\author{
Bridget Abell ${ }^{*}$, Paul Glasziou and Tammy Hoffmann
}

\begin{abstract}
Background: While the clinical benefits of exercise-based cardiac rehabilitation are well established, there is extensive variation in the interventions used within these trials. It is unknown whether variations in individual components of these exercise interventions provide different relative contributions to overall clinical outcomes. This study aims to systematically examine the relationship between individual components of the exercise intervention in cardiac rehabilitation (such as intensity and frequency) and clinical outcomes for people with coronary heart disease.

Methods: In this systematic review, eligible trials were identified via searches of databases (PubMed, Allied and Complementary Medicine, EMBASE, PEDro, Science Citation Index Expanded, CINAHL, The Cochrane Library, SPORTDiscus) from citation tracking and hand-searching. Studies were included if they were randomised trials of a structured exercise intervention (versus usual care) for participants with coronary heart disease and reported at least one of cardiovascular mortality, total mortality, myocardial infarction or revascularisation outcomes. Each included trial was assessed using the Cochrane Risk of Bias Tool. Authors were also contacted for missing intervention details or data. Random effects meta-analysis was performed to calculate a summary risk ratio (RR) with $95 \%$ confidence interval (Cl) for the effect of exercise on outcomes. Random effects meta-regression and subgroup analyses were conducted to examine the association between pre-specified co-variates (exercise components or trial characteristics) and each clinical outcome.

(Continued on next page)
\end{abstract}

\footnotetext{
* Correspondence: babell@bond.edu.au

Centre for Research in Evidence-Based Practice, Faculty of Health Sciences

and Medicine, Bond University, Gold Coast, Queensland 4229, Australia
} 
(Continued from previous page)

Results: Sixty-nine trials were included, evaluating 72 interventions which differed markedly in terms of exercise components. Exercise-based cardiac rehabilitation was effective in reducing cardiovascular mortality (RR 0.74, 95\% Cl 0.65 to 0.86 ), total mortality (RR $0.90,95 \% \mathrm{Cl} 0.83$ to 0.99 ) and myocardial infarction (RR $0.80,95 \% \mathrm{Cl} 0.70$ to 0.92 ). This effect generally demonstrated no significant differences across subgroups of patients who received various types of usual care, more or less than 150 min of exercise per week and of differing cardiac aetiologies. There was however some heterogeneity observed in the efficacy of cardiac rehabilitation in reducing total mortality based on the presence of lipid lowering therapy $\left(l^{2}=48 \%, p=0.15\right.$ for subgroup treatment interaction effect). No single exercise component was identified through meta-regression as a significant predictor of mortality outcomes, although reductions in both total (RR 0.81, $p=0.042$ ) and cardiovascular mortality (RR $0.72, p=0.045$ ) were observed in trials which reported high levels of participant exercise adherence, versus those which reported lower levels. A dose-response relationship was found between an increasing exercise session time and increasing risk of myocardial infarction (RR 1.01, $p=0.011$ ) and the highest intensity of exercise prescribed and an increasing risk of percutaneous coronary intervention (RR 1.05, $p=0.047$ ).

Conclusions: Exercise-based cardiac rehabilitation is effective at reducing important clinical outcomes in patients with coronary heart disease. While our analysis was constrained by the quality of included trials and missing information about intervention components, there appears to be little differential effect of variations in exercise intervention, particularly on mortality outcomes. Given the observed effect between higher adherence and improved outcomes, it may be more important to provide exercise-based cardiac rehabilitation programs which focus on achieving increased adherence to the exercise intervention.

\section{Key Points}

- Exercise-based cardiac rehabilitation interventions demonstrate considerable heterogeneity in format, yet few individual exercise training components predict better or worse clinical outcomes.

- Adherence to the exercise intervention as prescribed may however be important in affecting mortality outcomes.

- Clinicians should be aware that structured exercise programs can be flexible in design, without greatly impacting on the clinical outcomes expected.

\section{Background}

While ongoing improvements in diagnosis and treatment have resulted in a steady increase in survival rates from major coronary events $[1,2]$, the burden of coronary heart disease on public health remains a substantial problem. With an increasing number of patients surviving acute cardiac events, the impetus to use effective secondary prevention strategies grows. However, this need is not being met, with up to $40 \%$ of all coronary events occurring in patients who have previously been diagnosed or hospitalised with the disease [3-5], and well-documented evidencepractice gaps in the use of effective therapies $[6,7]$. Reducing the frequency of these recurrent events by enhancing the uptake of effective pharmacological and non-pharmacological interventions should therefore be considered an important health care priority.

While the benefits of exercise-based cardiac rehabilitation in the secondary prevention of coronary heart disease are well established [8-10], the complex nature of this intervention presents a substantial challenge to its implementation. Individual trial results vary considerably in terms of effectiveness, as well as in the type and 'dose' of exercise intervention provided, making it difficult to synthesise and translate these findings into practice in a way which provides optimal patient benefit. This problem has been compounded by incomplete reporting of intervention details in a substantial proportion of cardiac rehabilitation trials [11, 12]. In turn, this has hampered past attempts to understand how, and which, intervention characteristics relate to clinical outcomes.

Given the substantial variability of interventions in cardiac rehabilitation trials, it is pertinent to explore whether the differences in exercise interventions are contributing to the differences in observed effectiveness. While metaanalyses of these trials have provided evidence for the overall effectiveness of cardiac rehabilitation, vital content about the individual interventions and their effective components had been lost in the process of pooling these studies. An opportunity exists however to open this 'black box' of pooled interventions, by using meta-regression techniques to perform a more robust examination of the key intervention characteristics which may be associated with positive clinical outcomes [13, 14]. Past attempts to use this technique with cardiac rehabilitation have however only used a crude measure of exercise dose $[8,10,15]$, excluded exercise interventions without a multi-faceted secondary prevention approach [16] or examined only intermediate outcomes such as cardiorespiratory fitness $[17,18]$. 
The aim of this systematic review of randomised controlled trials of exercise-based cardiac rehabilitation for patients with coronary heart disease was to use meta-regression and subgroup meta-analysis to explore the contribution of individual exercise characteristics to clinical outcomes. This review expands on previous analyses by separating the exercise intervention into its smallest component parts, as well as obtaining and incorporating as many details as possible about previously unpublished intervention characteristics directly from trial authors.

\section{Methods}

\section{Inclusion Criteria}

Studies were eligible if they were randomised controlled trials with at least one arm that compared exercise-based cardiac rehabilitation to usual care, and which reported at least one of the following outcomes: total mortality, cardiovascular mortality, myocardial infarction, coronary artery bypass graft (CABG) or percutaneous coronary intervention (PCI). Trial participants could comprise men or women of any age who had been diagnosed with coronary heart disease, suffered a myocardial infarction, or undergone either CABG or PCI procedures.

Cardiac rehabilitation could have been provided in any setting (e.g. home, community or outpatient centre) but must have involved the prescription of a structured exercise program (either supervised or unsupervised), with or without the addition of lifestyle modification and counselling. Unsupervised home-based interventions were required to comprise a structured and detailed exercise prescription for participants (e.g. specific intensity, frequency and duration of individual sessions) with regular staff review, in a similar manner to centre-based programs. Including only structured exercise interventions (and excluding those which offered only general exercise advice, e.g. perform $150 \mathrm{~min}$ of exercise per week, walk daily) allowed for a more robust examination of the effect of specific exercise variables on outcomes.

Trials with a follow-up period of $<3$ months, with inadequate randomisation techniques, or those reporting on heart failure programs, were excluded. Trials published in abstract form only (from conference proceedings) were eligible for inclusion only if authors responded to email requests for further study information to determine if they met all eligibility criteria.

\section{Search Strategy and Selection of Studies}

We conducted a structured search (last run on 28 January 2016) of the following databases: PubMed, Allied and Complementary Medicine, EMBASE, PEDro, Science Citation Index Expanded (via Web Of Science), CINAHL, The Cochrane Library and SPORTDiscus. The search strategy was developed in conjunction with an experienced medical librarian, consisted of a variety of exercise-based rehabilitation terms combined with coronary heart disease descriptors and used methodological filters to limit the results to randomised controlled trials, meta-analyses and systematic reviews. Variations of the following were searched, using a combination of text words and index terms: coronary artery disease, ischemic heart disease, cardiovascular disease, myocardial infarction, angina, CABG, PTCA, rehabilitation, cardiac rehabilitation, exercise, physiotherapy, physical fitness, exercise training, training program, aerobic exercise, randomised controlled trial, random, controlled trial, meta analysis, systematic review and clinical trial (Additional file 1: Appendix S1 contains full search strategy).

In order to identify further trials, the reference lists of all eligible studies were hand-searched, as well as those of previously published cardiac rehabilitation meta-analyses and systematic reviews. The process was supplemented further with searches of conference proceedings in the field from the previous 2 years (World Congress of Cardiology, American Heart Association Scientific Sessions, European Society of Cardiology Congress and EuroPrevent), and by forward and backward citation tracking of all eligible studies in Web of Science. No restrictions were placed on language or date of publication.

The titles and abstracts of all articles retrieved from electronic searching and other sources were screened (by BA) for eligibility against the pre-specified inclusion criteria, and full-text publications were obtained for any potentially relevant studies. Any uncertainties regarding study eligibility were resolved through discussion with two other reviewers (PG, TH) until a consensus was reached.

\section{Data Extraction}

A standardised data extraction form (available on request) was used to extract the following: participant characteristics (gender, age, diagnosis), intervention(s) characteristics, follow-up duration, all relevant clinical outcomes reported, the type of care provided to the usual care comparison group, cardiovascular medication usage and details about the methodological quality of the trial. If multiple time points were reported, data from all which were greater than 3 months were extracted. Where multiple intervention arms were compared with usual care within a single study, each exercise arm was considered a separate intervention and data extracted accordingly.

In order to extract the individual exercise characteristics (used as co-variates in meta-regression analysis) from each included intervention in a standardised manner, a modified version of the Template for Intervention Description and Replication checklist was used [19] (Additional file 1: Table S2). Where the individual components of exercise interventions were missing or described in insufficient 
detail, attempts were made to locate this information in additional publications or by contacting each corresponding author $(n=62)$ via email. This process is described in further detail elsewhere [11]. While 28 authors responded to these requests and provided missing intervention details, 14 did not respond to numerous reminders. We were unable to locate contact details for a further 20 authors. A number of authors were also contacted to clarify outcome data.

\section{Outcomes}

Our primary outcome was cardiovascular mortality. Secondary outcomes were total mortality, myocardial infarction, CABG and PCI procedures. All outcomes were assessed for the time period beginning with randomisation until the end of last reported follow-up, thereby including events which occurred before, during and after the exercise intervention period for all trials. We chose not to use a combined endpoint for analysis, as although it may have increased the statistical power required to detect treatment effects, it can also be problematic in interpretation and generate misleading conclusions, particularly about the strength of reductions in mortality $[20,21]$. For this reason, the results of each outcome are presented separately.

\section{Risk of Bias of Included Trials}

The quality of each included trial was assessed according to the Cochrane Risk of Bias Tool [22]. Trials were rated as having a low, high or unclear risk of bias for the following criteria: sequence generation (adequate randomisation methods described), concealment of allocation, study blinding (of participants, personnel and outcomes), incomplete outcome data (participant attrition) and selective outcome reporting. Blinding of participants to exercise interventions is virtually impossible; however, the clinical outcomes in our analyses are unlikely to be influenced by knowledge of group allocation. We therefore considered the criterion of blinding in terms of outcome assessment. The degree of participant attrition was assessed at the outcome, rather than the study level. For example, a substantial number of participants may not have completed the trial (high-risk attrition at study level) but the authors were able to determine from medical records whether or not these missing participants were deceased at the trial end (low-risk attrition for mortality outcome).

\section{Statistical Analysis}

Both meta-analysis and meta-regression techniques were carried out in order to synthesise the individual trial data for each intervention and then examine the effect of individual intervention characteristics on each outcome. All comparisons of exercise-based cardiac rehabilitation versus usual care are expressed as relative risks (RRs) with 95\% confidence intervals (CI) which were calculated from reported event and population data in each trial. Effects were considered statistically significant at a $p$ value of $<0.05$. In order to minimise the bias due to missing participant data across a number of trials, the primary meta-analysis was conducted using a complete case analysis, as proposed in the Cochrane Handbook [23] and by Akl et al. [24]. This method uses, as the denominator, only those participants with complete outcome data recorded. Meta-analyses were performed in RevMan (Version 5.3, Cochrane Collaboration), with the relative risks of the outcome in each study pooled using a Mantel-Haenszel random effects model. Both the meta-analysis and meta-regression were performed using random effects models as clinical heterogeneity was expected given the wide variety of interventions and patients represented in the included trials. We tested for this heterogeneity in each meta-analysis using the Cochrane Q statistic and also calculated the $I^{2}$ to quantify the percentage of variation in effectiveness across studies which would be considered beyond a chance finding. Potential for publication bias was examined using funnel plots.

In trials with multiple intervention arms, combining these into a single group is the recommended approach for meta-analysis to avoid unit-of-analysis errors arising from correlated intervention effects. Using this approach however does not allow an investigation into the differences between treatment arms required by this analysis. Hence, we chose to use another recognised approach, dividing proportionally the number of events and total population of the shared usual care group between intervention arm comparisons, avoiding 'double-counting' while still allowing exploration of heterogeneity across differing interventions [23].

We also used approaches proposed by Akl et al. [25] to test the robustness of effect estimates to missing participant data (due to withdrawal, drop-out, etc.). This was done by conducting two different sensitivity analyses using plausible assumptions to impute missing participant event data for each trial. The first assumed that the incidence of events in all missing participants was the same as that observed among those followed up in the control arm of the same trial. The second approach imputed missing participant data relative to those with complete data in the same trial arm, assuming that those missing in the intervention arm had an increased event incidence of 1.5 compared to those followed up, and the control arm the same event incidence (1.0) in those with complete and missing data. We additionally performed further sensitivity analyses excluding those trials assessed at high risk of bias for missing outcome data and those published in only abstract form or as a doctoral thesis. 


\section{Subgroup Analyses}

We conducted subgroup analyses to investigate differences in each outcome for four broad cardiac rehabilitation program comparisons which were specified a priori, based on issues raised in previous research or due to current guideline recommendations for cardiac rehabilitation and physical activity. These comparisons were (1) trials which enrolled only patients with a diagnosis of myocardial infarction vs those with mixed aetiologies [13]; (2) programs which contained $\geq 150 \mathrm{~min}$ of prescribed weekly exercise vs those with $<150$ min per week [26, 27]; (3) programs with a more intensive usual care arm vs programs with a standard usual care arm $[12,28]$; and (4) programs that included lipid lowering statin therapy vs those that did not $[13,29]$. Information about the concomitant use of lipid lowering therapy in each trial arm was extracted directly from studies where possible. Where this was not reported, we used the recruitment dates and duration of follow-up of participants to ascertain if statin use was likely, based on increasing clinical use from 1994 [30]. All subgroup differences were tested for significance using RevMan, and an $I^{2}$ statistic was also computed in order to estimate the degree of subgroup variability due to true differences rather than chance.

\section{Meta-regression}

The effect of individual exercise intervention characteristics on both primary and secondary outcomes was explored by using the 'metareg' command in Stata (Version 14, StataCorp LP) [31] to perform univariate random effects meta-regression. The median year of trial recruitment and pre-specified exercise program characteristics of intervention duration (months), exercise intensity (\%HRmax), session frequency (times per week), session time (minutes), intervention provider (physician in team vs not), mode of exercise (aerobic only vs aerobic plus resistance training), delivery of exercise (group vs individual) and level of adherence to the prescribed exercise regimen (modelled as a categorical variable) were entered as co-variates. Adherence was extracted as the mean proportion of all prescribed centre and/or home-based exercise sessions completed by participants. We used established equations and tables $[32,33]$ to convert exercise intensities reported in varying formats across studies (e.g. Borg scale, \% heart rate reserve, \% $\mathrm{VO}_{2 \max }$ ) into one consistent format (\% maximal heart rate) for all analyses.

Co-variates were considered statistically significant predictors of outcome if the $p$ value associated with the $R R$ of the meta-regression was $<0.05$. Multiple testing was accounted for by using the 'permute 5000' option in Stata to examine any variables which reached statistical significance [31]. $R^{2}$ was calculated to explain the percentage of between study variance explained by any particular co-variate. To assess whether any characteristics which displayed statistical significance in univariate analysis were independently associated with improved outcomes, we combined any co-variates with a $p$ value of $\leq 0.2$ in a multivariable model and used a stepwise backwards elimination approach to remove those which did not contribute significantly to the model.

\section{Results}

\section{Trial Selection}

Sixty-eight publications [34-101] met our inclusion criteria (see Fig. 1 for PRISMA flow chart), reporting on clinical outcomes and follow-up of 69 different trials (one publication [98] reported outcomes of a collaborative study which involved several individual trial centres). Several trials included multiple intervention arms [39, 71, 72, 87] resulting in a total of 72 individual exercise interventions.

\section{Trial Characteristics}

Of the included 69 trials (characteristics described in Table 1), one was only reported in abstract form (for which the author provided data), one was a published doctoral thesis and the remainder were full-text publications. Most (65) were published in English, with one each in Italian and Danish and two in Russian (all of which were translated for inclusion). Publication years ranged from 1975 to 2015, and the majority of trials (59\%) took place in Europe. Trial size varied from 28 to 1813 participants; however, most were small, with a median of 134 participants. The median duration of follow-up across all trials was 3 years but varied widely: the longest follow-up reported for mortality outcomes was 19 years and for myocardial infarction, CABG and PCI 10 years.

\section{Participant Characteristics}

Of the 13,423 participants with coronary heart disease included in all trials, the mean age in individual trials ranged from 49 to 80 years, with an average age of 54 years (Table 1$)$. The majority of participants were male $(83 \%)$, with only 10 trials containing more than $25 \%$ of female participants and 26 trials (38\%) comprising male participants only. A large proportion of trials $(43 / 69 ; 62 \%)$ included only patients after myocardial infarction; however, those published from 1990 onward often included patients diagnosed with coronary artery disease $(n=8 ; 12 \%)$, postPCI $(n=5 ; 7 \%)$, post-CABG $(n=2 ; 3 \%)$ or a combination of these cardiac aetiologies $(n=11 ; 16 \%)$.

\section{Intervention Characteristics}

Despite our repeated attempts to obtain missing information [11], many details about the individual components of exercise interventions remained unknown, with $22 \%$ of interventions with missing details for at least one 


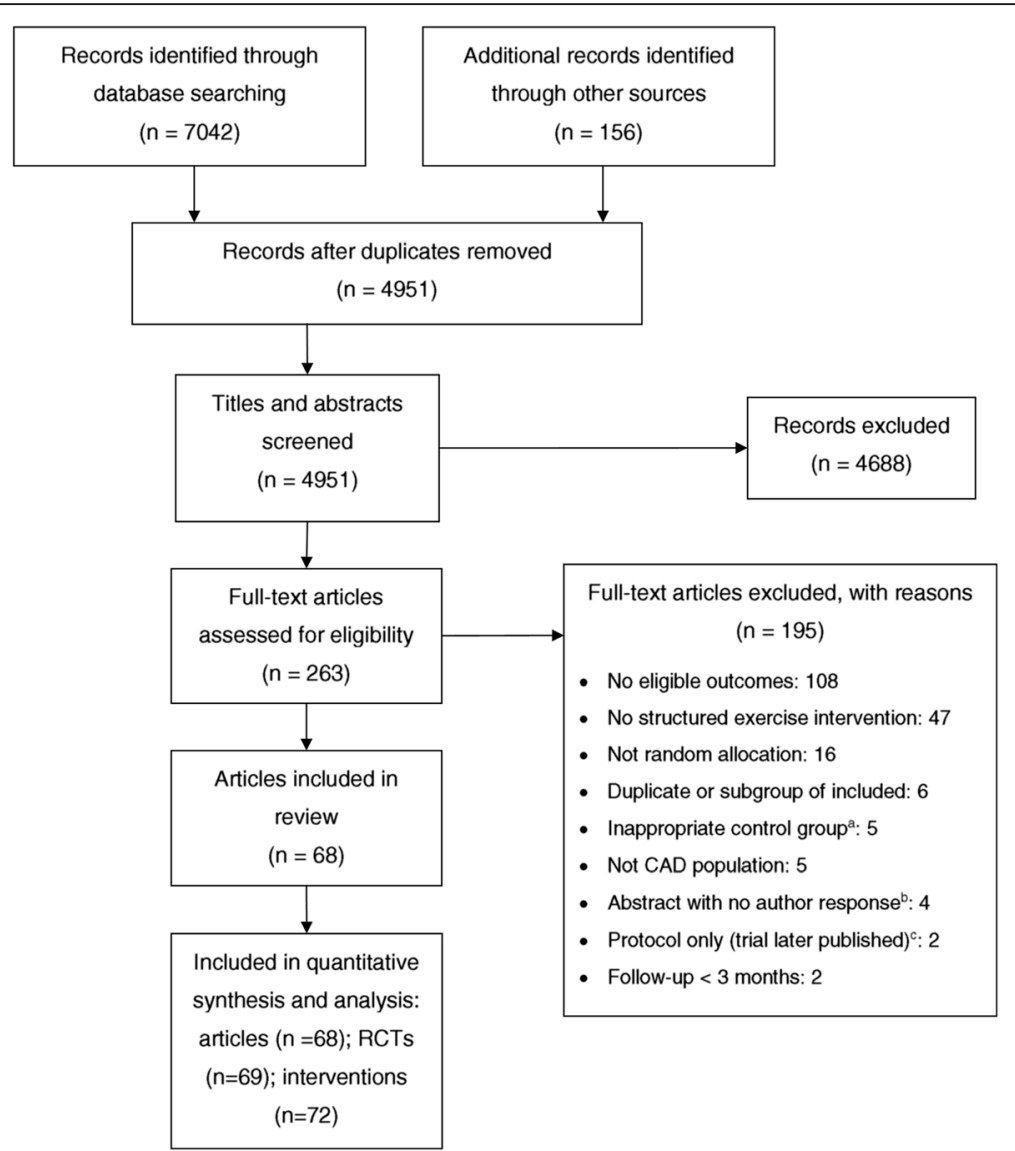

Fig. 1 PRISMA flow diagram of the screening and selection of trials. a Different type of exercise or surgical intervention as comparator. $b$ We were unable to assess the eligibility of one trial published as a conference abstract as the author did not respond to repeated email inquiries. Two other conference abstracts described trials with outcomes eligible for inclusion; however, these could not be included as authors were not yet ready to share their results. One further abstract was eligible for inclusion; however, the author failed to respond to requests for data (abstract references in Additional file 1: Appendix S3). c One of these trials was later excluded and one included. CAD coronary artery disease, RCT randomised controlled trial

characteristic of session time, session frequency or exercise intensity. Hence, while these trials and interventions are included in the overall meta-analysis, they could not be entered into the meta-regression where these covariates were missing.

\section{What, How, Where and Who Details of the Interventions}

An overview of the main details of each intervention is provided in Table 1. Exercise training was conducted in supervised outpatient, residential or community-based settings in the majority of interventions, with only $18 \% \quad(n=13)$ containing sessions which were conducted entirely in an unsupervised, home-based environment. Consequently, most interventions also used some form of group exercise training (80\%; $n=53$; six missing details). All 72 interventions used aerobic exercise training, with $54 \%(n=31 ; 15$ missing) also containing resistance training or callisthenic body-weight exercises. Interval training was used in eight interventions and circuit-based exercises in seven, while six interventions consisted only of home-based walking programs. In 53 (74\%) interventions, exercise was combined with other secondary prevention strategies such as risk factor education, counselling and stress management, while the remainder provided exercise training as a standalone intervention. Allied health staff, such as physiotherapists and exercise specialists, were directly involved in the prescription and supervision of exercise training in more than half of all interventions $(n=32$; $59 \%$; 18 missing details), with a physician routinely contributing to exercise supervision in 16 interventions.

\section{Prescribed Exercise Intervention Dose, Intensity and Adherence}

Across all interventions (missing for 21 interventions), participants were reported to begin exercise training a mean of 4.8 weeks (SD 2.8) after the initial diagnosis or cardiac incident. The prescribed 'dose' of exercise training in these interventions varied widely (Table 2). The median 


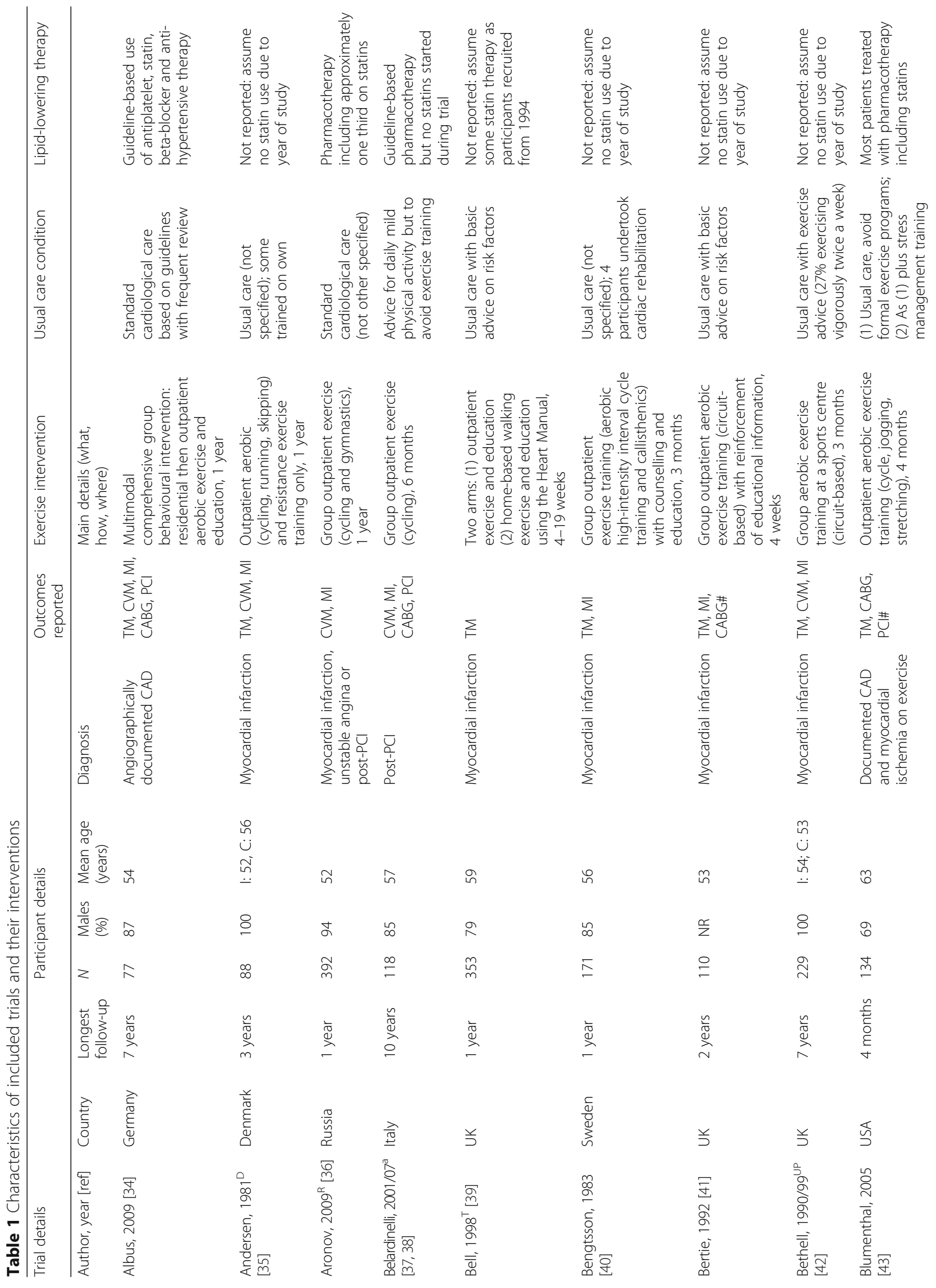




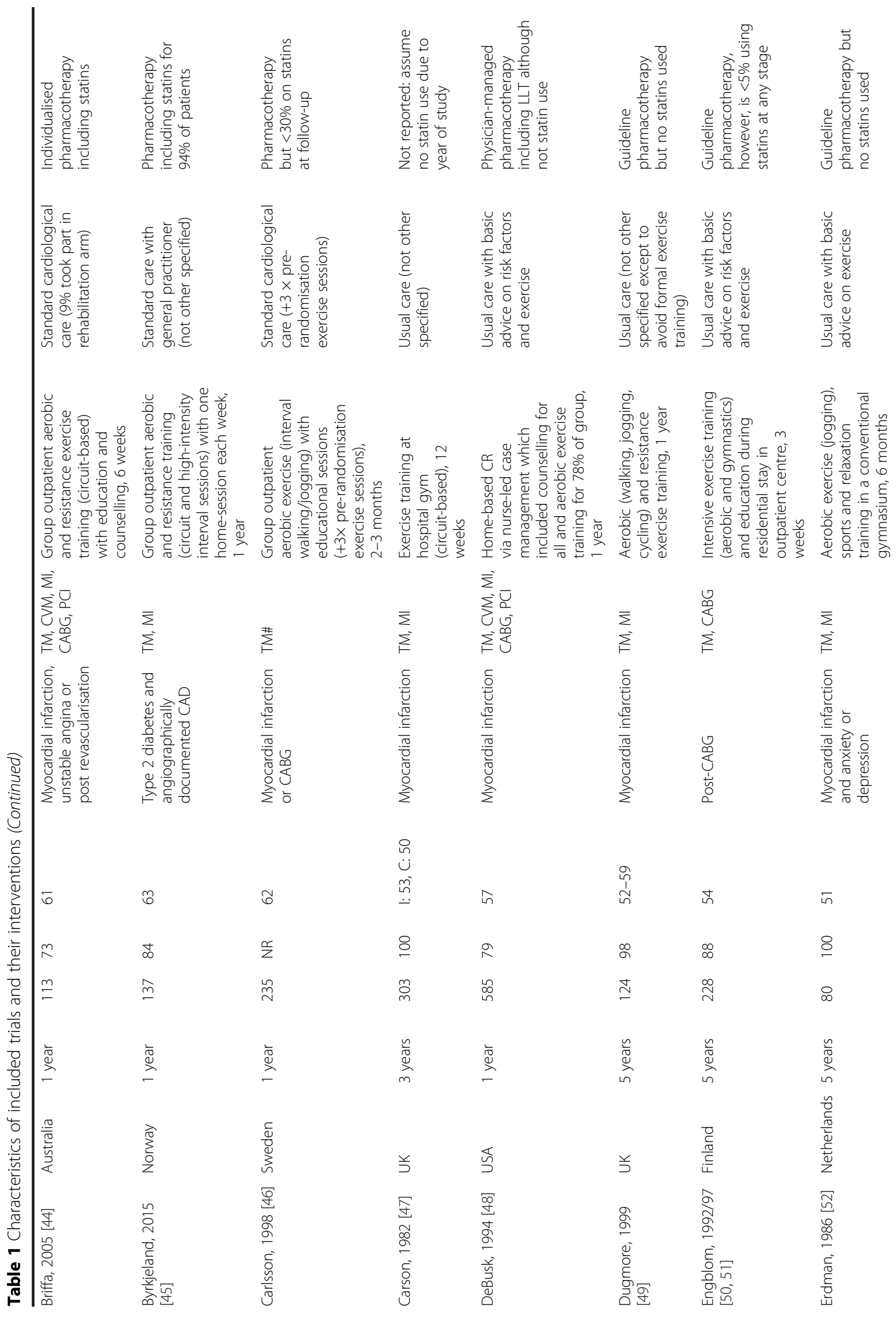




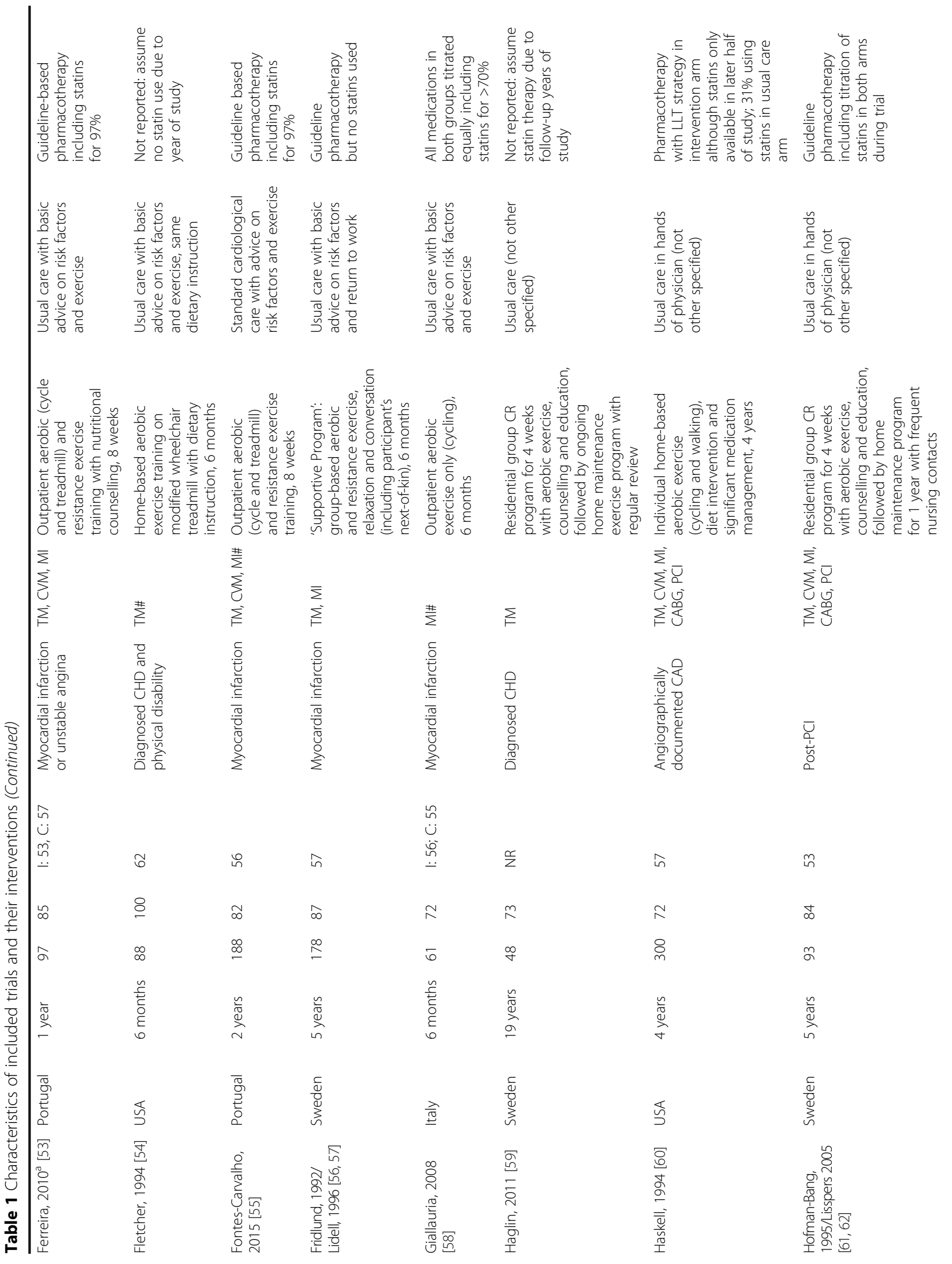




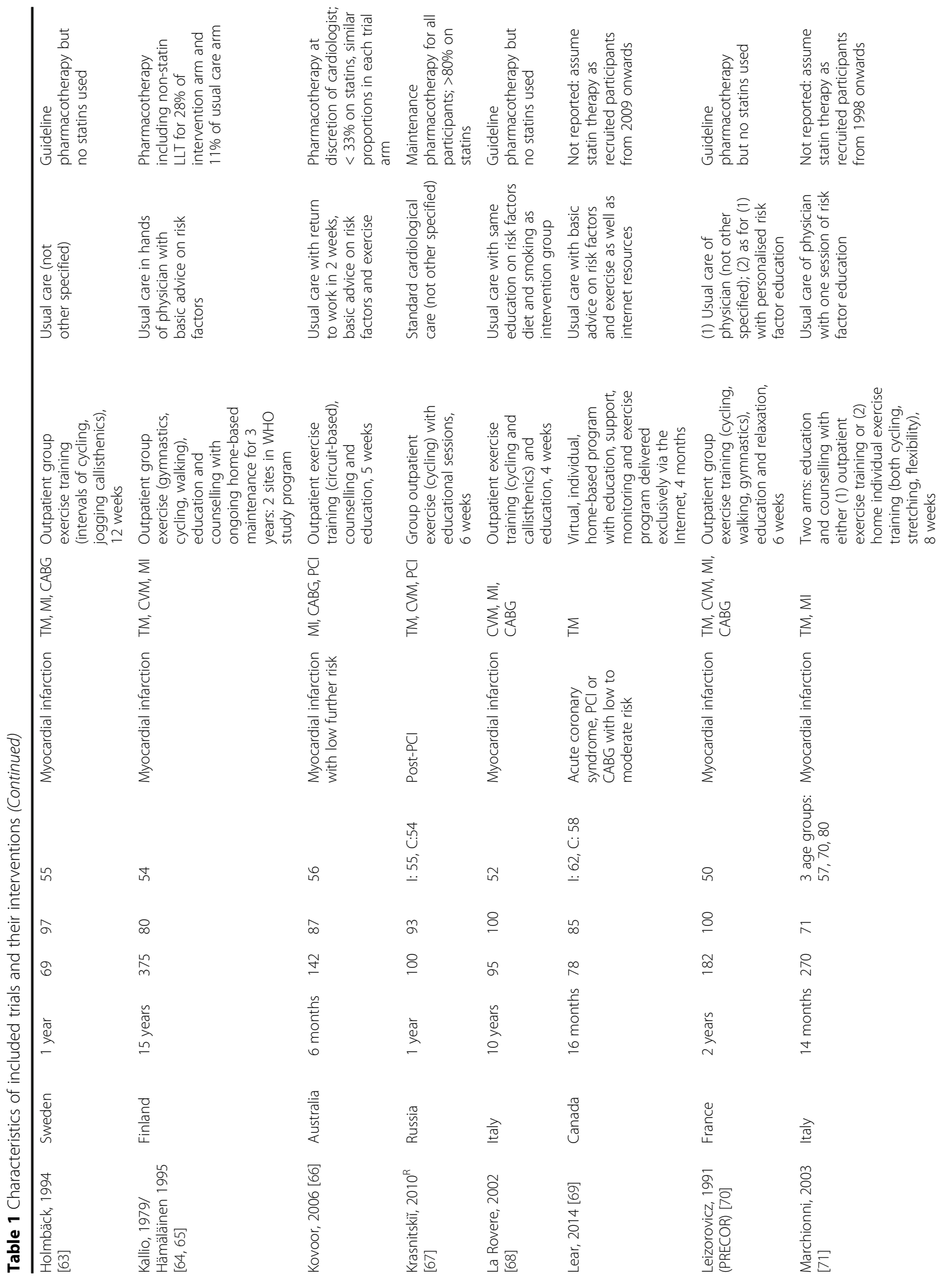




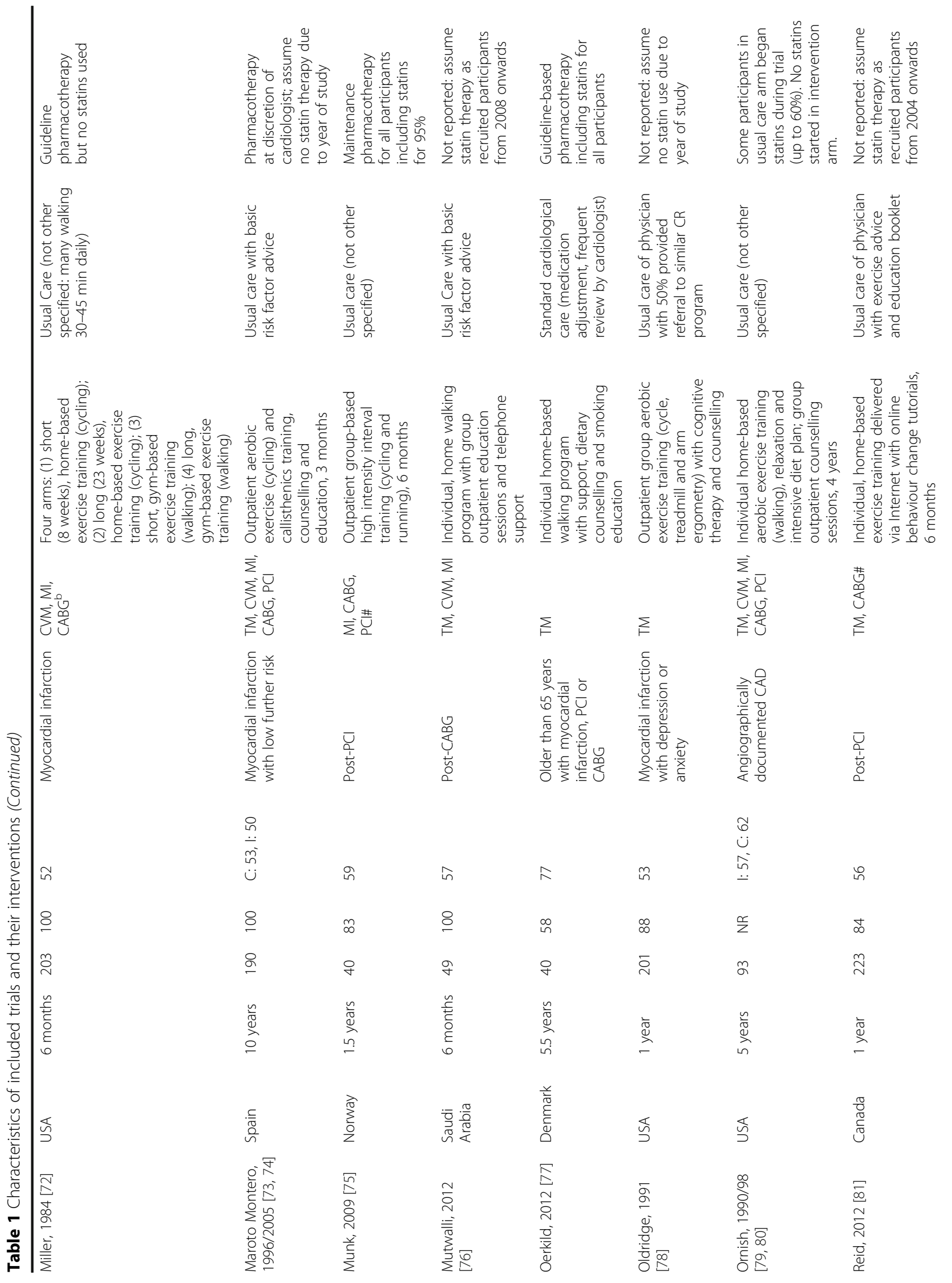




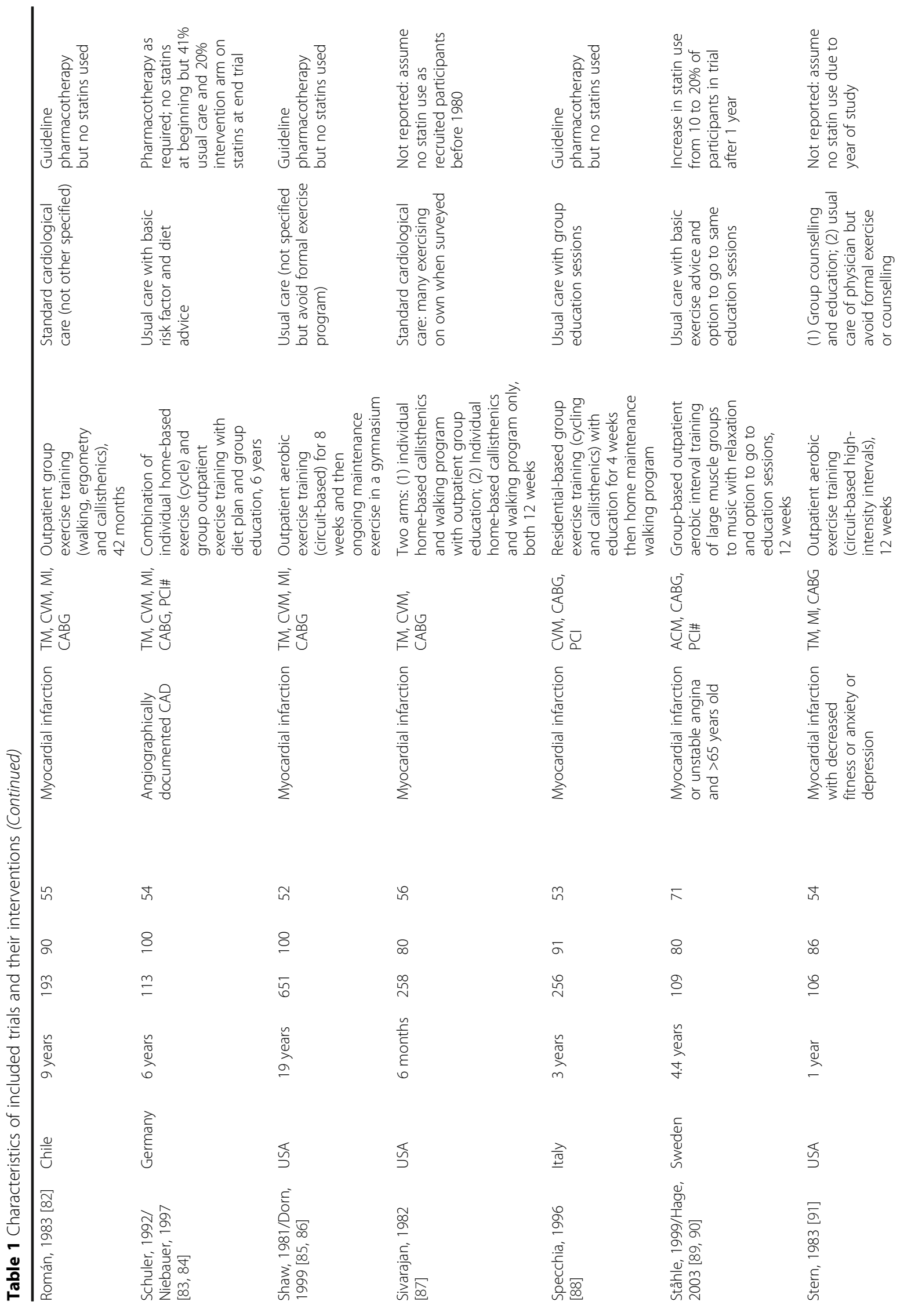




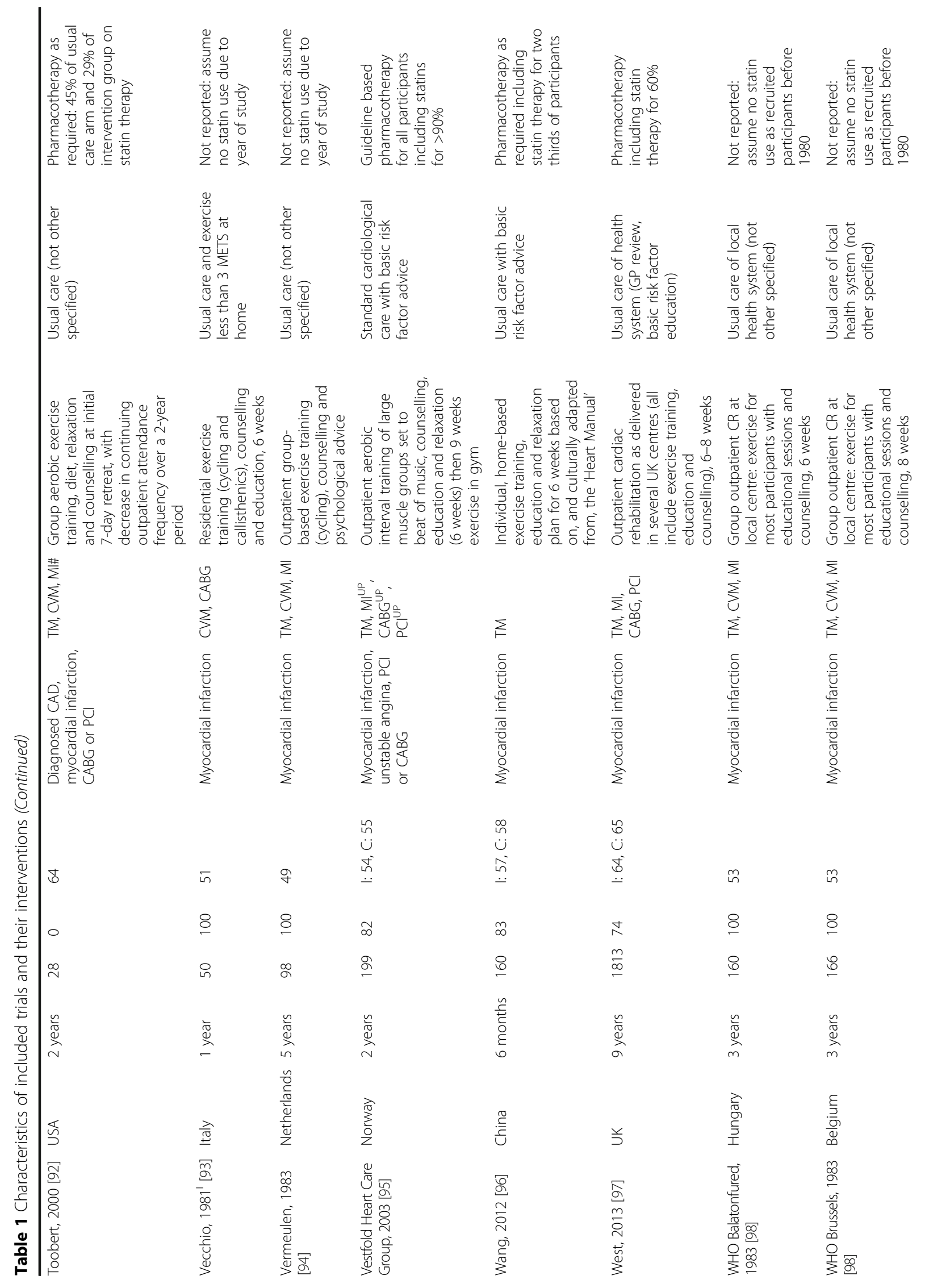




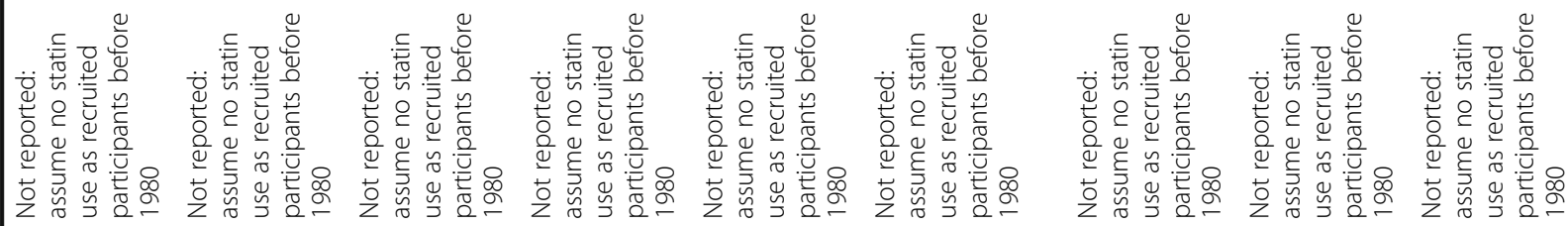

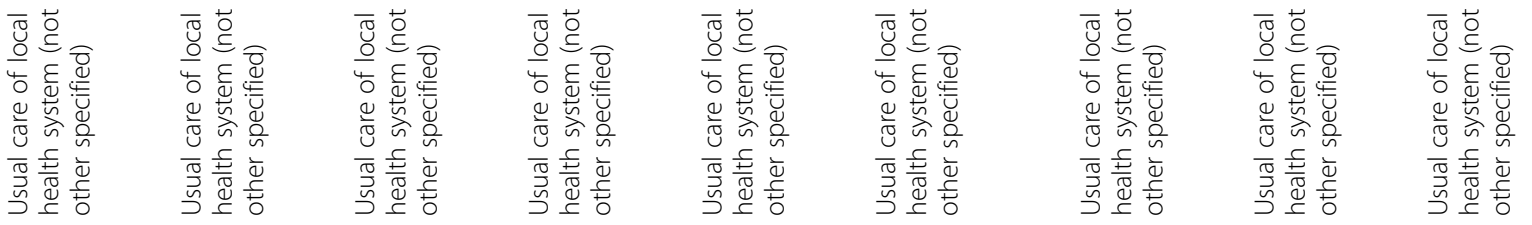

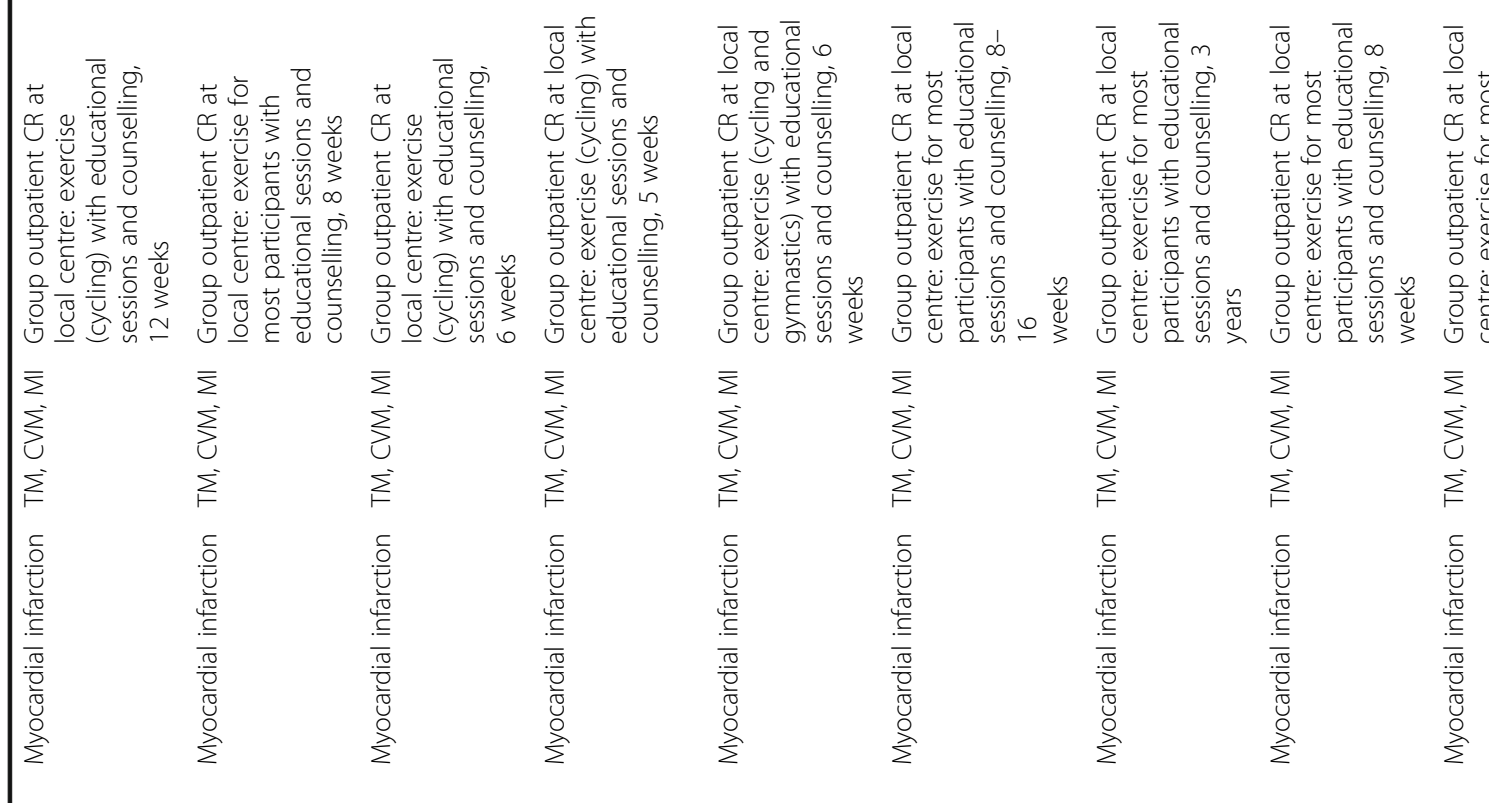

n

in

in

n

n

n

nn

ผn

nก

$\therefore$

ষ্ণ

$\stackrel{8}{\circ}$

8

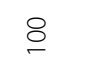

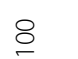

$\stackrel{8}{8}$

$\stackrel{8}{\circ}$

8

芩

$\stackrel{\varrho}{=}$

$\stackrel{\infty}{\circ}$

$\stackrel{\llcorner}{=}$

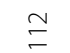

ติ

$\stackrel{\forall}{=}$

$\stackrel{\frac{n}{\pi}}{\stackrel{n}{\pi}} \quad \stackrel{\frac{n}{\pi}}{\stackrel{n}{n}}$

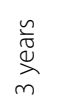

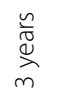

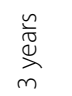

$\stackrel{\frac{n}{0}}{\stackrel{n}{\pi}}$

$\underset{\substack{\tilde{\pi}\\}}{\stackrel{n}{\pi}}$

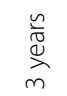

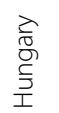

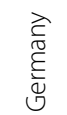

离

$\frac{\varepsilon}{\overline{5}}$

竞

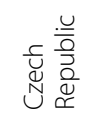

좉

票

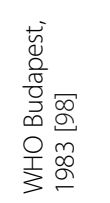

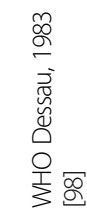

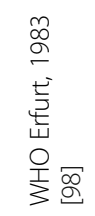

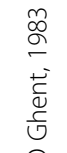

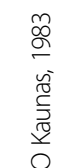

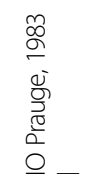

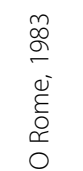

o

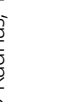

오욜

亮要

这

喜要 


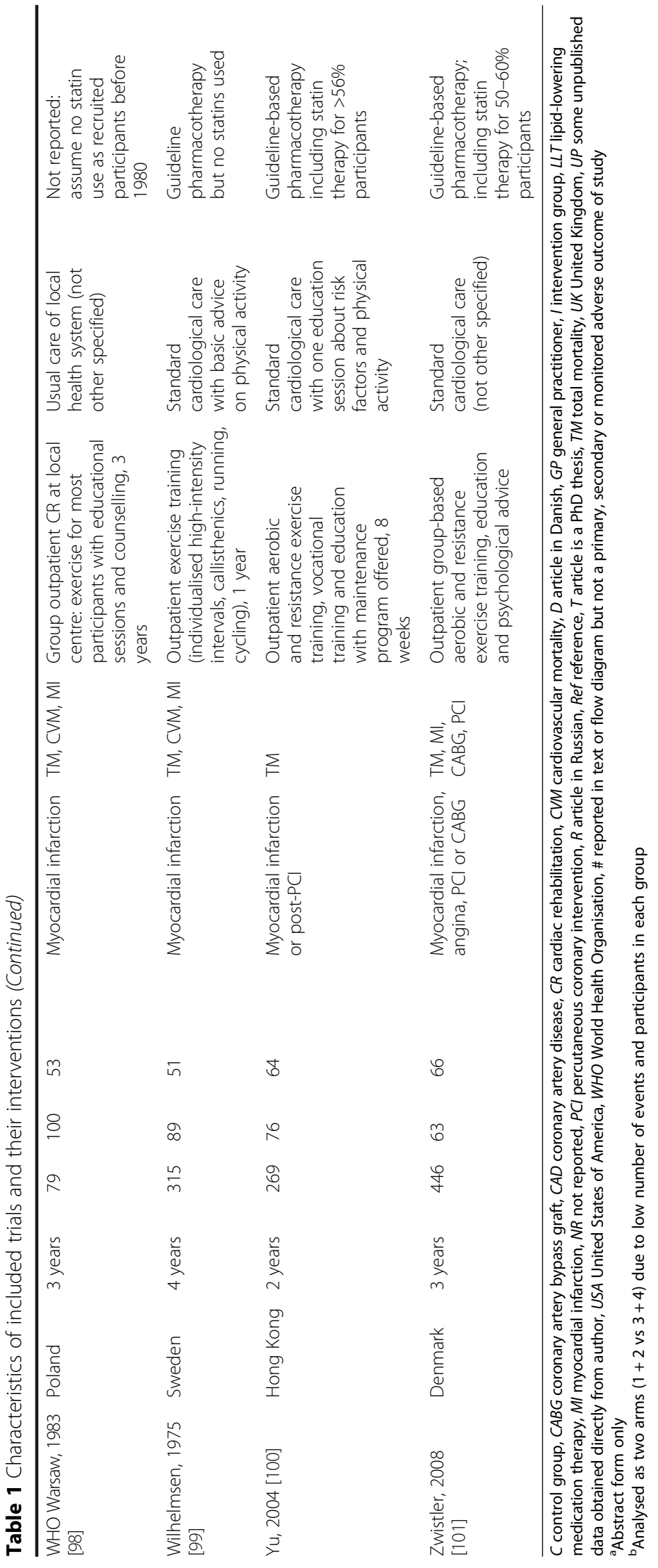




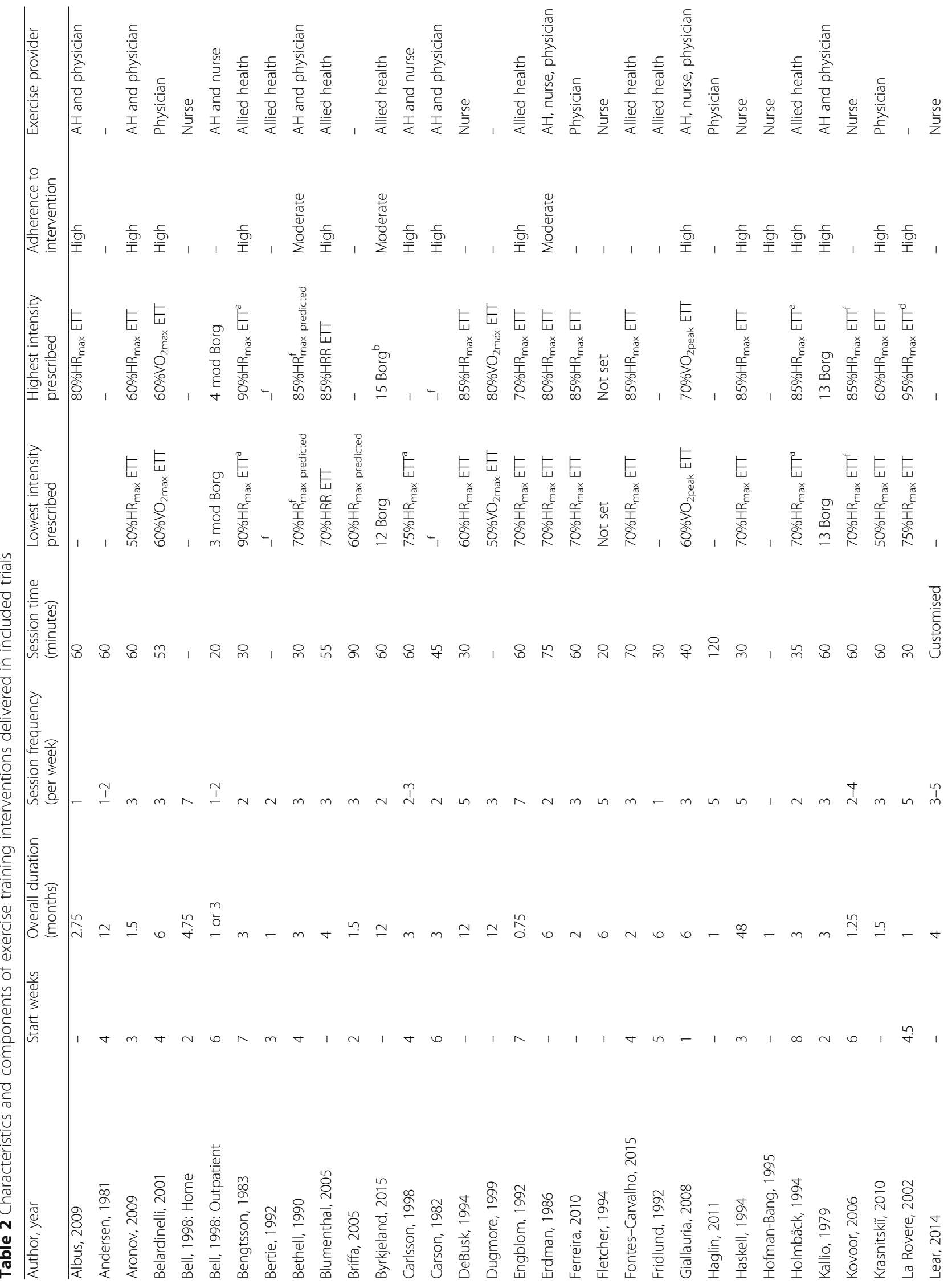




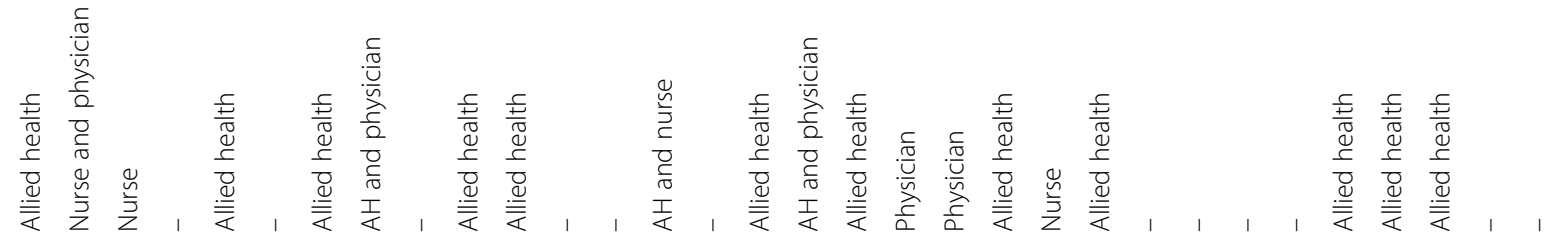

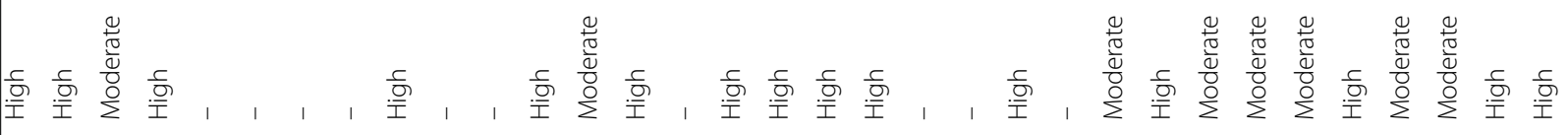

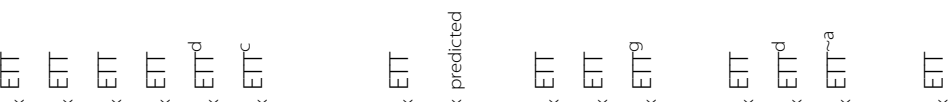

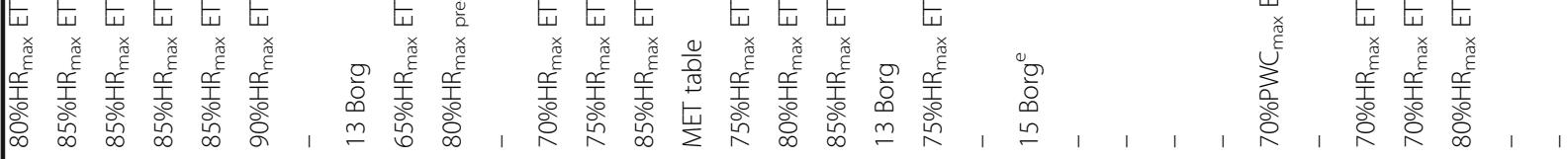

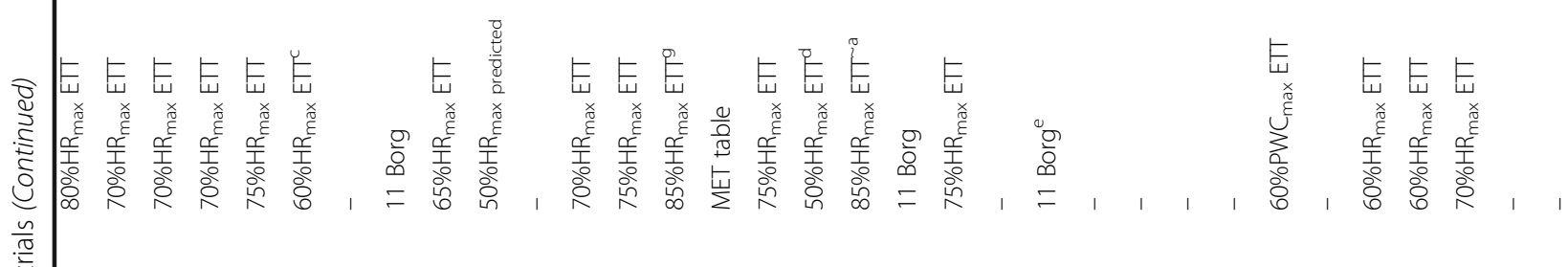

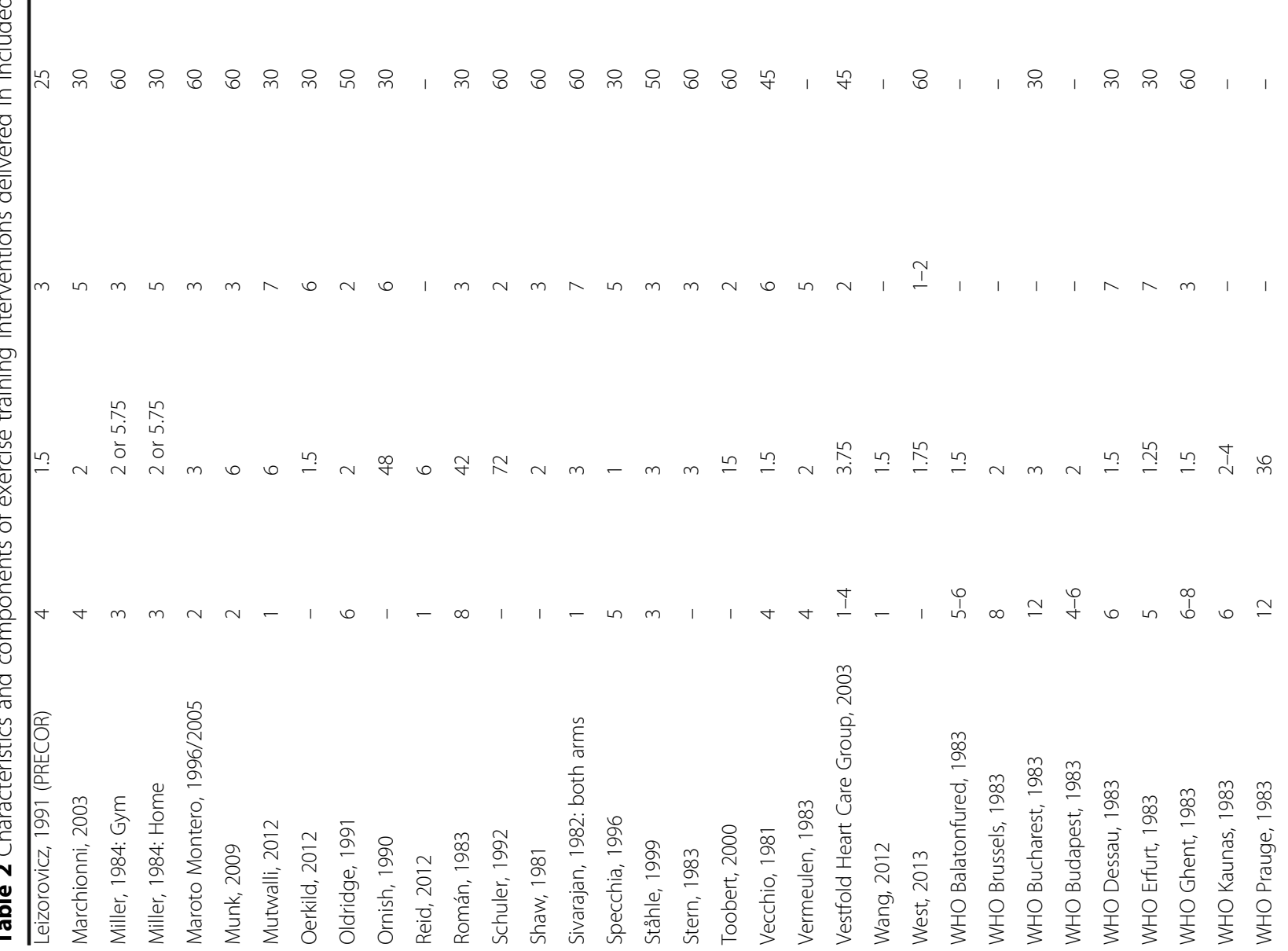




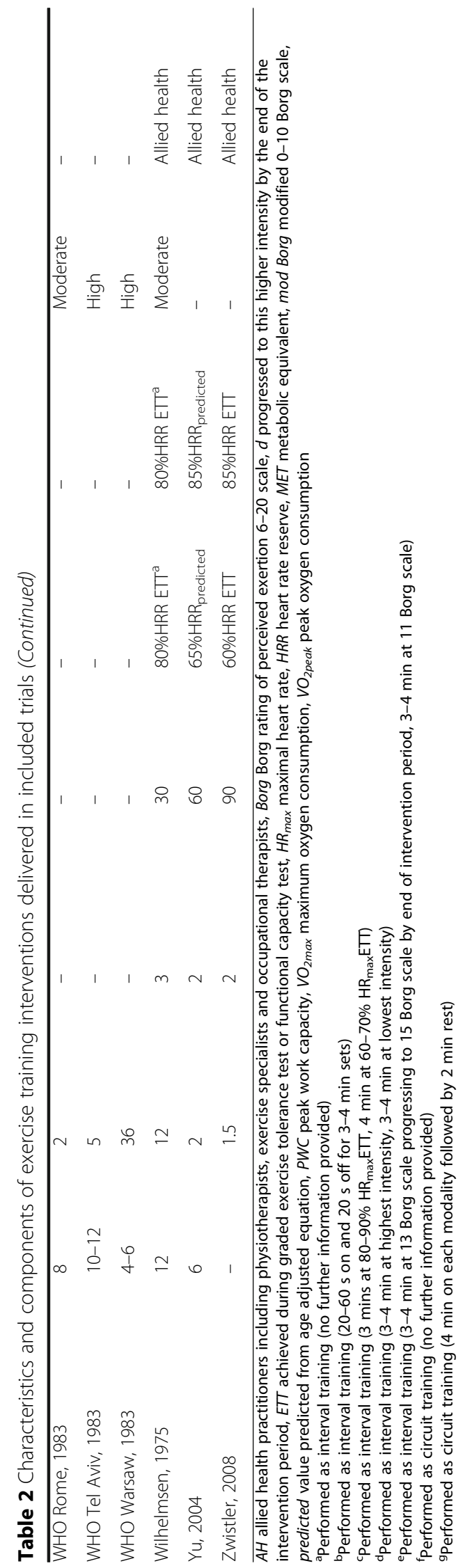


duration of exercise interventions was 3 months; however, the shortest intervention lasted 3 weeks and one continued for 6 years. Exercise sessions occurred at a median frequency of three times per week, lasting a mean of 49 min $(\mathrm{SD}=19)$ including warm-up and cooldown. The combination of prescribed session duration and frequency in individual interventions exceeded the guideline recommendation of $150 \mathrm{~min}$ of exercise per week in $67 \%$ of interventions ( $n=38 ; 16$ missing), with the structure of 18 interventions providing $<150 \mathrm{~min}$ of exercise per week.

Where reported ( $n=51$, Table 2$)$, exercise intensity was most often prescribed using a target range, rather than a single value for the level of effort required. Given the range of prescribed intensities within a single intervention, some degree of individualisation is assumed, along with differing rates of progression to the top of the prescribed range. This range was most commonly based on a percentage of the actual peak heart rate achieved during symptom-limited maximal exercise testing; however, in four cases, it was based on an age-predicted maximal heart rate. We also noted exercise intensity prescribed in several other formats including the Borg scale $(n=6)$, METs $(n=1)$, or peak $\mathrm{VO}_{2}(n=3)$ or work capacity $(n=1)$ measured during symptom-limited exercise testing. Once converted to the same scale, the mean minimum exercise intensity prescribed across all interventions was $68 \%$ of the maximal heart rate, increasing up to a mean of $80 \%$ at the top of the prescribed range. Overall, the majority of interventions prescribed levels of exercise which could be classified as either moderate-to-vigorous $(n=6 ; 12 \%)$, vigorous $(n=28 ; 55 \%)$ or vigorous-to-high $(n=5 ; 10 \%)$ in intensity [33]. Interventions prescribing interval training generally took the format of vigorous (rather than high or maximal) intervals lasting 3-4 min interspersed with 2-3 min of active or passive recovery (refer to Table 2 footnotes for details).

Adherence to the prescribed exercise regimen was reported for 46 interventions, and ranged from $60-100 \%$. For supervised interventions $(n=42)$, this information was routinely collected by program or trial staff based on attendance, while unsupervised interventions $(n=4)$ relied on self-reported participant exercise logs, or data collected via the phone each week. Almost three quarters of interventions $(n=33)$ reported levels of adherence which we classified as high $(\geq 75 \%$ all prescribed exercise sessions completed), with the remainder displaying moderate adherence levels (50-74\% of sessions completed).

\section{Usual Care Comparisons}

The care provided in the usual care arm of trials varied greatly (Table 1$)$. For many comparisons $(n=31 ; 41 \%)$, the exact nature of care received in this arm was unspecified, described only as usual care in the hands of a physician or local health service. Participants in the control arm of 10 other comparisons were reported to receive 'standard cardiological care', which usually consisted of guideline-based treatment, including regular cardiology or nursing review, and medication titration. The remaining 31 control comparison groups also received either usual or cardiological care, with the addition of risk factor and/or general physical activity advice (e.g. eat less fat, walk daily). Unlike home-based intervention arms, these control arm interventions did not take the form of a prescribed and structured program but consisted of printed or on-line material, a single education session, face-to-face discussion or personalised advice. The first two types of control arms were classified as 'usual care' in this review, whereas we considered participants in the latter type of trials to have been delivered 'usual care plus lifestyle advice' in the control arm.

Guideline-based medication regimens which included statin therapy were reportedly used at baseline, during the trial, or throughout follow-up, in 24 (34\%) of the control arm comparisons. In a further seven comparisons $(10 \%)$, statin therapy was not explicitly reported but probable given the dates of participant recruitment. Lipid-lowering therapy was either not begun in the control arm, or reported as not used, in 17 comparisons (24\%) and was unlikely used in a further 24 comparisons with recruitment and follow-up periods preceding 1994. Overall, this resulted in statin use in the control arm (matched with comparable use in the intervention arm) for $40 \%$ of comparisons, $56 \%$ of comparisons without statin use in either arm and three trials $[46,48,60]$ in which the intervention arm included a specific pharmacological lipid-lowering strategy compared to the control arm (Table 1).

\section{Publication Bias and Quality Assessment Publication Bias}

The funnel plot for the primary outcome of cardiovascular mortality did not suggest asymmetry or publication bias (Additional file 1: Figure S4a). Similarly, evidence of publication bias was not observed for the outcomes of total mortality, myocardial infarction or CABG. The funnel plot for the PCI outcome however displayed possible asymmetry, suggesting the absence of small studies with favourable effects from the analysis (Additional file 1: Figure S4b).

\section{Allocation: Random Sequence Generation and Concealment}

The reported methods used for random sequence generation were considered to be at low risk of selection bias in 34 trials (49\%). One study [59] was rated to be at a high risk of bias, as while initial randomisation occurred from all referrals using a number table; when a participant allocated to the intervention arm was not able to take part in the treatment clinic, a new patient was 
randomly selected from the referral population to be a case. In the remaining 34 interventions, while randomisation was reported, the risk attributable to sequence generation was unclear due to a lack of information. The allocation sequence was reported as adequately concealed in only a quarter of trials $(n=17)$. The remaining 52 trials did not provide enough information to make a judgment about the risk of bias in this domain.

\section{Blinding: Participants, Personnel, and Outcome Assessment}

Due to the inherent nature of exercise training, blinding of participants and providers to the intervention received did not occur in any trial. However, in seven trials (10\%), the outcome assessors were blinded to participant group, and a further 23 (33\%) used methods of outcome assessment (e.g. medical records, registry data) which would be unlikely to suffer from bias due to lack of blinding and we judged these trials to be at low risk of bias. Whether or not blinding of outcome assessment occurred or objective data sources were used was unclear in 36 trials (52\%). Three trials which explicitly stated that the study and outcome assessment were unblinded were rated at high risk of bias.

\section{Incomplete Outcome Data}

In terms of mortality outcomes, 11 trials (16\%) did not account for a loss of participant outcome data exceeding $15 \%$ and were consequently rated as at a high risk of attrition bias. These trials had a mean of $25 \%$ missing data, with one [79] unable to account for outcomes of almost $50 \%$ of randomised participants, who later declined to consent to study procedures (although this dropout was equal across both trial arms). In regards to the other outcomes of myocardial infarction, CABG and PCI, 19\% of trials $(n=13)$ were rated at high risk of attrition bias.

Overall, poor reporting meant that $86 \%$ of trials were rated as an unclear risk of bias in one or more of the above domains (Additional file 1: Table S5). Eight trials (12\%) were assessed to be at low risk of bias across all four domains, while 17 (25\%) were rated at high risk of bias for one or more domains, most usually incomplete outcome data. Additionally, bias due to selective outcome reporting could only be assessed for five of the included studies $[55,71,75,81,101]$ in which all pre-specified primary and secondary outcomes in the protocols were reported in the published trials. Consequently, most information in this review is from studies rated at unclear risk of bias, and the proportion of studies at high risk of bias for missing outcome data needs to be considered when interpreting the results (Additional file 1: Figures S5a and S5b).

\section{Primary Outcome: Cardiovascular Mortality}

Cardiovascular mortality, reported in 31 trials (comprising 44 different interventions and 6926 participants), showed a statistically significant reduction with exercisebased cardiac rehabilitation compared to usual care over a follow-up period of 10 years in length (RR $0.74,95 \% \mathrm{CI}$ 0.65 to $0.86, p<0.0001$ ) (Fig. 2). When considering followup out to 19 years (additional information provided in two trials), a smaller reduction in risk was observed (RR 0.82, $95 \%$ CI 0.73 to $0.91, p=0.0004$ ). No evidence of heterogeneity was observed in either analysis $\left(I^{2}=0 \%\right)$. Sensitivity analysis also demonstrated the effect estimates to be robust to missing participant data (Additional file 1: Table S6a) and publication type (Additional file 1: Table S7a).

\section{Analysis of Intervention Components}

Subgroup analyses with interventions stratified based on population diagnosis $\left(I^{2}=0 \%, p=0.60\right.$ for interaction effect), minutes of prescribed exercise per week $\left(I^{2}=0 \%\right.$, $p=0.81)$, type of usual care $\left(I^{2}=0 \%, p=0.72\right)$ or the use of lipid-lowering therapy $\left(I^{2}=0 \%, p=0.60\right)$ did not demonstrate any differences in effect on cardiovascular mortality (Additional file 1: Table S8a).

Univariate meta-regression analysis found no significant effect of the year of recruitment to the trial, exercise mode and exercise provider; how the exercise was delivered; or the prescribed intervention duration, session frequency, time or intensity on cardiovascular mortality outcomes (Additional file 1: Table S9a). A significant relationship was however observed between the level of adherence to the exercise intervention and cardiovascular mortality (Fig. 3), with a $28 \%$ reduction in relative risk (RR 0.72, 95\% CI 0.52-0.99, $p=0.045$ ) observed for those comparisons reporting high levels of adherence to the prescribed exercise intervention compared to those reporting only moderate levels of adherence. No other co-variates met the pre-specified $p$ value cut-off for entry into the multivariate model.

\section{Secondary Outcome: Total Mortality}

The pooled meta-analysis found a $10 \%$ reduction in overall mortality risk with exercise-based cardiac rehabilitation compared to usual care over a follow-up period of 10 years (Fig. 4). When extending the follow-up period out to 19 years, no demonstrable reduction in overall mortality was observed (RR 0.97, 95\% CI 0.90 to $1.04, p=0.37$ ). These intervention effects were also less robust to missing data with the sensitivity analysis suggesting a trend towards non-significance (Additional file 1: Table S6b). No evidence of heterogeneity was observed in either analysis $\left(I^{2}=0 \%\right)$.

\section{Analysis of Intervention Components}

Subgroup analyses with interventions stratified based on population diagnosis, minutes of prescribed exercise per week and the type of usual care did not demonstrate any differences in effect on total mortality 


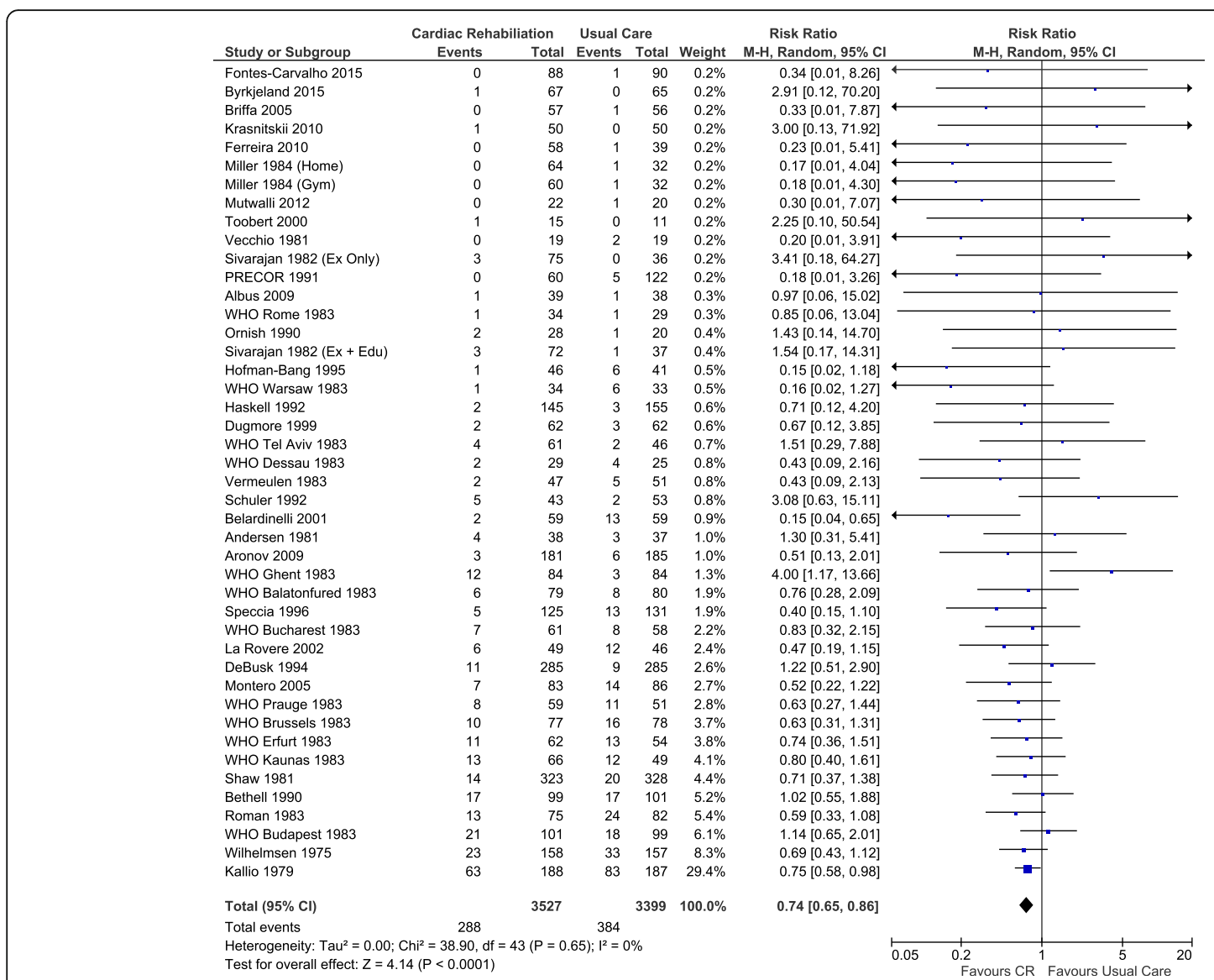

Fig. 2 Forest plot of the effect of exercise-based cardiac rehabilitation (vs usual care) on cardiovascular mortality across all types of interventions, Cl confidence interval, CR cardiac rehabilitation

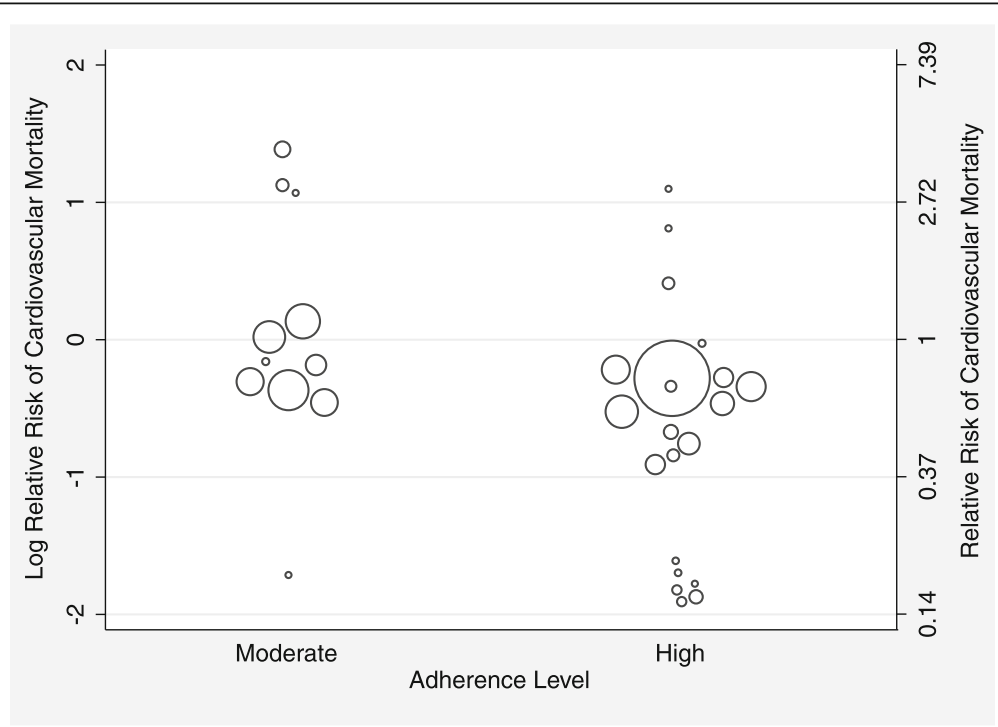

Fig. 3 Relationship between the reported level of exercise intervention adherence and the relative risk of cardiovascular mortality compared to usual care. Each intervention is represented by a circle; the size of the circle is proportional to the number of participants undertaking that intervention. A log RR of $>0$ represents an increase in risk and $<0$ a decrease 


\begin{tabular}{|c|c|c|c|c|c|c|c|c|c|c|}
\hline \multirow[t]{2}{*}{ Outcome } & \multicolumn{2}{|c|}{ Studies Interventions } & \multicolumn{2}{|c|}{ Cardiac Rehabilitation } & \multicolumn{2}{|c|}{ Usual Care } & \multirow{2}{*}{$\begin{array}{c}\text { Risk Ratio } \\
\text { M-H, Random, } 95 \% \mathrm{Cl}\end{array}$} & \multirow{2}{*}{$\begin{array}{c}\text { Risk Ratio } \\
\text { M-H, Random, } 95 \% \text { Cl }\end{array}$} & \multirow[t]{2}{*}{ p-value } & \multirow[t]{2}{*}{$1^{2}$} \\
\hline & $\mathbf{n}$ & $\mathbf{n}$ & Events & Total & Events & Total & & & & \\
\hline Cardiovascular Mortality & 31 & 44 & 288 & 3527 & 384 & 3399 & $0.74(0.65-0.86)$ & & $<0.0001$ & $0 \%$ \\
\hline Total Mortality & 47 & 60 & 701 & 5792 & 763 & 5487 & $0.90(0.83-0.99)$ & & 0.03 & $0 \%$ \\
\hline Myocardial Infarction & 41 & 53 & 336 & 5025 & 415 & 4915 & $0.80(0.70-0.92)$ & & 0.002 & $0 \%$ \\
\hline Coronary Artery Bypass Graft & 29 & 31 & 206 & 3370 & 210 & 3360 & $0.96(0.79-1.15)$ & & 0.64 & $0 \%$ \\
\hline Percutaneus Coronary Intervention & 18 & 18 & 187 & 2308 & 236 & 2357 & $0.77(0.59-1.00)$ & & 0.05 & $37 \%$ \\
\hline & & & & & & & 0. & 0 & & \\
\hline
\end{tabular}

Fig. 4 The effect of exercise-based cardiac rehabilitation versus usual care on coronary heart disease outcomes. Diamonds represent the pooled summary estimate of random effects Mantel-Haenszel meta-analysis for each outcome. CR cardiac rehabilitation, UC usual care

(Additional file 1: Table S8b). Moderate heterogeneity however $\left(I^{2}=48 \%, p=0.15\right.$ for interaction) was observed among subgroups divided by use of concomitant lipidlowering therapy, suggesting this may account for some of the variability in the effect observed. The trend observed was for exercise-based cardiac rehabilitation interventions to have a reduced effect in the presence of lipid-lowering therapy, although this effect did not reach significance.

Univariate meta-regression analysis found that exercise adherence was the only co-variate which significantly predicted total mortality outcomes (Additional file 1: Table S9b). A $19 \%$ reduction in relative risk ( $R R$ 0.81, 95\% CI 0.66-0.996, $p=0.042$ ) was observed for those comparisons reporting high levels of adherence to the prescribed exercise intervention compared to those reporting only moderate levels of adherence. While several co-variates met the pre-specified $p$ value cut-off for entry into the multivariable model, after backwards elimination of non-significant predictors, only adherence remained.

\section{Secondary Outcome: Myocardial Infarction}

Random effects meta-analysis found that exercise-based cardiac rehabilitation produced a $20 \%$ reduction in myocardial infarction events compared to usual care (Fig. 4). This effect was also robust to missing data and publication type in sensitivity analysis (Additional file 1: Table S6c;
Additional file 1: Table S7c), and no evidence of heterogeneity was observed $\left(I^{2}=0 \%\right)$.

\section{Analysis of Intervention Components}

Subgroup analyses with interventions stratified based on population diagnosis, minutes of prescribed exercise per week and type of usual care did not demonstrate any differences in effect on myocardial infarction events (Additional file 1: Table S8c). Low to moderate heterogeneity $\left(I^{2}=33 \%, p=0.23\right.$ for interaction effect) was observed among subgroups divided by use of concomitant lipid-lowering therapy, which was largely due to the difference in effect observed in the subgroup of two trials providing statin therapy as part of the intervention arm.

Univariate meta-regression analysis found only one co-variate that significantly predicted myocardial infarction outcomes (Additional file 1: Table S9c). A significant positive relationship was observed between the total time prescribed for exercise each session and the risk of myocardial infarction (Fig. 5). That is, for every 1 min increase in time (between 25 and $90 \mathrm{~min}$ ), the relative risk of myocardial infarction with the exercise intervention vs usual care increased by $1 \%$. While several co-variates met the pre-specified $p$ value cut-off for entry into the multivariable model, after backwards elimination of non-significant predictors, only exercise time remained. Due to a moderate pairwise correlation

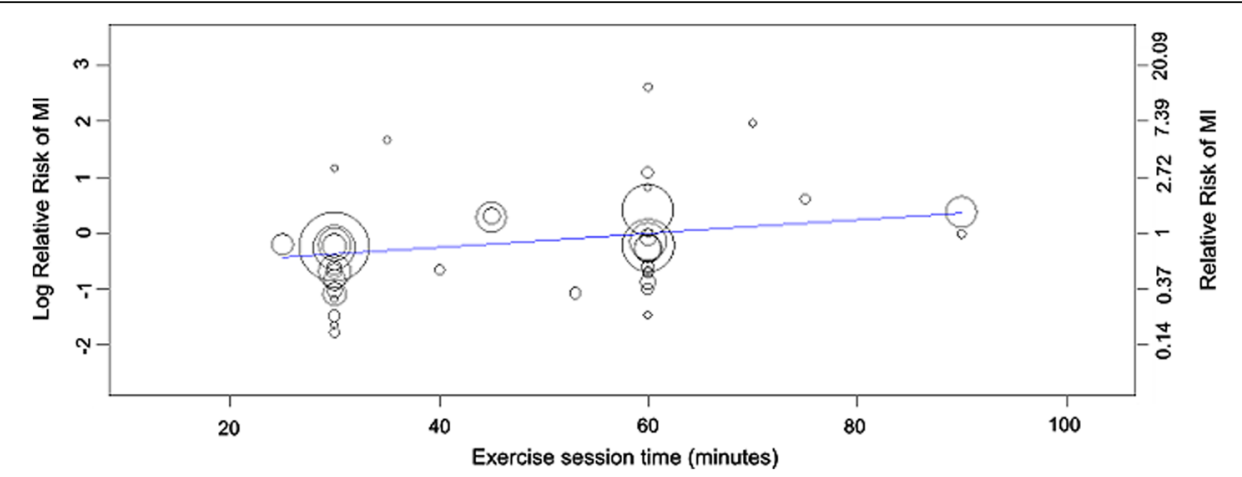

Fig. 5 Relationship between the prescribed time for exercise training each session and the relative risk of myocardial infarction compared to usual care $(p=0.011)$. Each intervention is represented by a circle; the size of the circle is proportional to the number of participants undertaking that intervention. A log RR of $>0$ represents an increase in risk and $<0$ a decrease 
between session time and session frequency $(r=-0.512)$, some potential multicollinearity may have been observed between these two co-variates in the multivariable analysis. However, repeating the analysis accounting for this fact did not produce different results about potential predictors of myocardial infarction outcomes.

\section{Secondary Outcome: Coronary Artery Bypass Grafting}

Random effects meta-analysis found no demonstrable reduction in the number of participants who required coronary artery bypass grafting (CABG) in the exercise-based cardiac rehabilitation interventions compared to usual care (Fig. 4). Sensitivity analysis for missing outcome data did not change this effect estimate (Additional file 1: Table S6d), and no evidence of heterogeneity was observed $\left(I^{2}=0 \%\right)$.

\section{Analysis of Intervention Components}

Subgroup analyses with interventions stratified based on minutes of the prescribed exercise per week, the type of usual care or the use of lipid-lowering therapy did not find any differences in effect on the number of CABG procedures performed (Additional file 1: Table S8d). However, a significant interaction was found between the population diagnosis and outcome, with exercise interventions undertaken by participants with mixed aetiologies, demonstrating a greater reduction in CABG event rate compared to usual care than those which comprised purely myocardial infarction patients $\left(p=0.04, I^{2}=76 \%\right)$.

Univariate meta-regression analysis did not find any covariates to have an effect on CABG outcomes (Additional file 1: Table S9d). Prescribed intervention duration was the only co-variate which met the pre-specified $p$ value cut-off for entry into the multivariate model; consequently, multivariate meta-regression was not performed for this outcome.
Secondary Outcome: Percutaneous Coronary Intervention The pooled meta-analysis found no difference between exercise-based cardiac rehabilitation and usual care in reducing PCI events (Fig. 4), with some possibly important heterogeneity observed $\left(I^{2}=37 \%, p=0.06\right)$. Sensitivity analysis for missing outcome data did not change this effect estimate or substantially reduce the degree of heterogeneity (Additional file 1: Table S6e). Excluding trial data obtained only in abstract form reduced heterogeneity without substantially changing the effect estimate (Additional file 1: Table S7d).

\section{Analysis of Intervention Components}

Subgroup analyses with interventions stratified based on population diagnosis, type of usual care or minutes of prescribed exercise per week did not demonstrate any differences in effect on the number of PCI procedures performed (Additional file 1: Table S8e). Some nonsignificant heterogeneity $\left(I^{2}=21 \%, p=0.28\right)$ was observed for subgroups stratified by use of lipid-lowering therapy. However, stratifying the overall meta-analysis based on this factor could not account for the overall heterogeneity observed.

Univariate meta-regression analysis found no significant effect of the year of recruitment to the trial, exercise mode, format of exercise training or prescribed intervention duration, session frequency or time on $\mathrm{PCI}$ outcomes (Additional file 1: Table S9e). A significant positive relationship was however observed between the highest level of intensity prescribed and the risk of PCI (Fig. 6). That is, for every $1 \%$ increase in maximal heart rate prescribed (between 60 and $91 \% \mathrm{HR}_{\max }$ ), the relative risk of PCI with the intervention compared to usual care increased by $5 \%$. Additionally, in interventions where the team providing exercise training included medical practitioners, as opposed to nursing or allied health staff alone, the risk

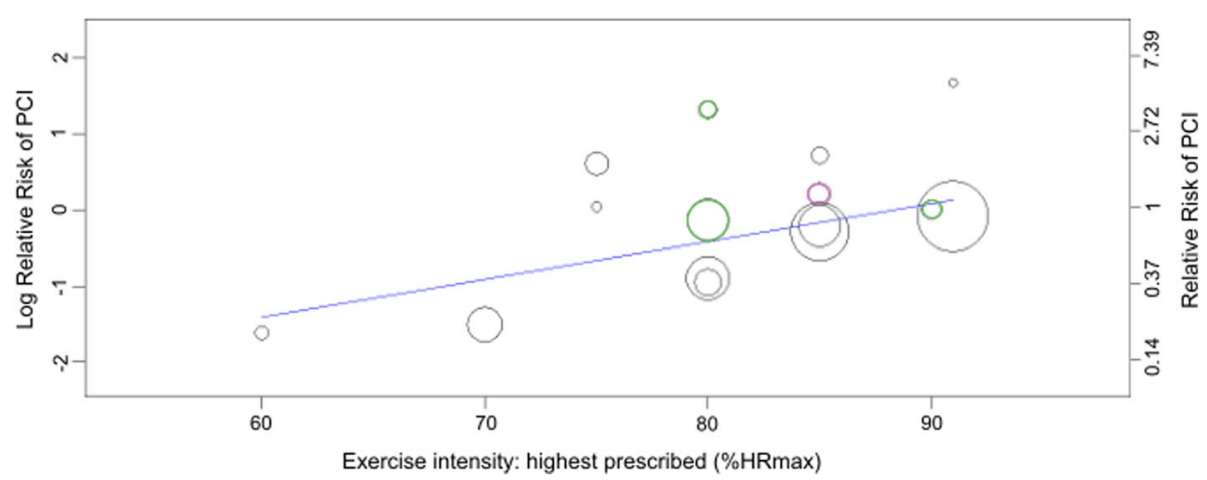

Fig. 6 Relationship between the highest intensity of exercise prescribed (as a percentage of maximal heart rate) and the relative risk of percutaneous coronary intervention compared to usual care $(p=0.047)$. Each intervention is represented by a circle; the size of the circle is proportional to the number of participants undertaking that intervention. A log RR of $>0$ represents an increase in risk and $<0$ a decrease. Circles coloured green represent interventions for which the highest intensity was only prescribed for brief periods during interval training. Circles coloured purple represent interventions for which the highest intensity was only prescribed during the work periods of circuit training 
of PCI was significantly decreased (RR $0.30,95 \%$ CI $0.14-0.62, p=0.004)$. None of the co-variates which met the pre-specified $p$ value cut-off for entry into the multivariate model remained after backwards elimination of non-significant predictors.

\section{Discussion}

This meta-analysis demonstrates exercise-based cardiac rehabilitation to be effective in reducing total and cardiovascular mortality, as well as myocardial infarction, in participants with coronary heart disease. This effect was largely consistent across subgroups of patients who received various types of usual care, more or less than $150 \mathrm{~min}$ of exercise per week, and of differing cardiac aetiologies. Additionally, the effectiveness of cardiac rehabilitation to reduce PCI procedures displayed borderline significance, which may be important given that the funnel plot displayed a possible absence of small studies reporting positive effects.

While the largest proportion of included trials and interventions remained traditional group-based programs of supervised aerobic (and often resistance) training, our review also found an expanding range of interventions including home walking programs, high-intensity interval training, case management and Internet technologies. Consequently, the prescribed dose of exercise training varied widely, with some interventions offering a substantially greater volume of training than others. However, we were unable to demonstrate evidence for the effectiveness of any one specific exercise component, such as intensity, frequency, session time or type, on reducing mortality outcomes. A relationship was observed however between increasing levels of adherence to exercise training and a reduction in subsequent mortality. In contrast, we found a detrimental effect of increasing the prescribed exercise time and intensity on myocardial infarction and PCI outcomes respectively.

Overall, the results of our pooled analyses are generally consistent with previous meta-analyses of exercise-based cardiac rehabilitation. These studies also found a significant reduction in the relative risk of cardiovascular mortality, with a similar magnitude of effect observed in the most recent analyses $[8,15]$, which also included patients of mixed aetiologies. The inability of cardiac rehabilitation to significantly reduce the frequency of CABG and PCI events was also reported in these two earlier studies. The previously observed effects of cardiac rehabilitation on myocardial infarction and total mortality have however been mixed.

While earlier meta-analyses found significant reductions in total mortality of up to $20-30 \%[12,15,102$, 103], the most recent review [8], which represented a broader range of participants and trials conducted in the modern treatment era, failed to find such a benefit.
While we observed a significant $10 \%$ reduction in total mortality in our sample, this effect was less robust to missing data in sensitivity analysis and provides some evidence to support the hypothesis that the effect of cardiac rehabilitation on total mortality may be attenuated when considering a wider range of participants in the modern treatment era.

\section{Exercise-Based Cardiac Rehabilitation in the Modern Treatment Era}

It has been previously suggested that the benefits of exercise-based cardiac rehabilitation over usual care may be incremental in the modern era, with the advent of lipidlowering therapy and optimal medical treatment $[8,97]$. Previous meta-analyses $[8,10,15,102]$ have examined this hypothesis with subgroup analysis comparing the outcomes of trials published before and after 1994/95, with this date acting as a surrogate for changing practices in treatment reported after this time [30]. While these studies found no significant subgroup differences and consequently claimed the benefits of cardiac rehabilitation to be maintained in the modern era, the use of publication date in this manner has several limitations. Firstly, it is a crude measure of when a trial was conducted and may not accurately reflect treatment practices at the time of publication. Trials with long recruitment and follow-up periods, along with delays in publication, mean that not all post-1994 trials were necessarily conducted in the modern treatment era. For example, one trial published in 2002 [68] reported a 10-year follow-up of patients recruited in 1984 and 1985 and was conducted wholly in the pre-statin era. Additionally, at least one study published post-1995 [37] explicitly excluded the use of lipid-lowering therapy. Including these trials in their respective year-based subgroups may not provide a true reflection of changes in care. Furthermore, even in the modern treatment era, the level of usual care provided to the control arm can vary widely, from followup with a physician to educational packages or sessions and targeted guideline advice about lifestyle modification. This is an important consideration as Janssen et al. [28] have previously shown that there may be a dilution of effectiveness for secondary prevention interventions when compared to control groups where usual care is optimal.

Therefore, to assess the impact of cardiac rehabilitation treatment in the modern era, we examined the effects of both usual care and lipid-lowering therapy separately, as well as performing meta-regression analysis based on the median year of reported trial recruitment. Subgroup analysis was not able to replicate the findings of Janssen, with no significant differentiation in the effects of cardiac rehabilitation with the varying levels of usual care provided. This seems to support the importance of providing structured exercise training even in the presence of other lifestyle change 
measures, such as physical activity advice, education or counselling. This is an important consideration given that the level of usual care provided in clinical practice may often be less ideal than that delivered in clinical trials. While subgroup analysis was not able to display a significantly different effect of cardiac rehabilitation in programs with lipid-lowering therapy compared to those without, we did observe some evidence that total mortality was less likely to be reduced by cardiac rehabilitation in the presence of lipid-lowering therapy. This was more pronounced when excluding those studies with a specific lipidlowering strategy in the intervention arm ( $p$ for subgroup differences $=0.07, I^{2}=70 \%$ ).

While this attenuation of effect may be due to statin therapy alone, it is more likely confounded by other improvements in medical management and patient demographics in these later trials which included lipid-lowering therapy. Essentially, as hypothesised, statins may be acting as a surrogate marker for improved medical management over time. This argument is in agreement with the most recent Cochrane review on the topic where a trend was observed via meta-regression for smaller reductions in total mortality with cardiac rehabilitation trials published in more recent years [8]. However, our analysis using a more clinically meaningful co-variate for trial year found no trend or significant association between the median year of participant recruitment to the trial and the subsequent risk of mortality. Together, these findings suggest that while pharmaceuticals may affect the ability of cardiac rehabilitation to reduce overall mortality to some extent, the importance of this intervention in reducing clinical events in the modern treatment era does not appear to be greatly diminished.

\section{The Impact of Exercise Intervention Characteristics and Prescribed 'Dose'}

Our findings extend those of previous meta-analyses of exercise training in cardiac rehabilitation, which have also found no effect of prescribed exercise dose (reported as program duration $\times$ session time $\times$ session frequency) on clinical outcomes $[8,10,15]$. However, analysing the effect of exercise interventions based on such a crude overall measure of 'dose' may have acted to mask the effects of the individual components in these earlier analyses, and none took into account varying exercise intensities. Additionally, the level of poor intervention reporting we observed in the majority of trials would have hampered the ability of researchers to obtain all three elements required for the calculation of dose (e.g. the most recent Cochrane review [8] was only able to examine the effect of 18 doses of exercise on cardiovascular mortality out of 24 trials). Our use of individual exercise components, along with efforts to obtain missing descriptions, meant that we were able to explore a greater range of dose comparisons in analysis, with increased power to detect a true effect. The finding that few differences in effect were present, despite these improvements in methodology, supports the conclusions of the original meta-analyses. Additionally, they are consistent with a systematic review which found no effect of exercise session frequency or duration on improvements in fitness in cardiac rehabilitation patients [18].

It could be argued that energy expenditure expressed as either MET-hours or kilocalories would have provided the most useful measure of exercise dose accounting for various combinations of intensity, frequency and duration of exercise sessions prescribed within an intervention. However, the combination of missing intervention characteristics and a lack of knowledge about baseline $\mathrm{VO}_{2}$ values in the majority of included trials meant that we were unable to obtain the necessary information to calculate energy expenditure within most individual interventions. Consequently, we could not examine the relationship between this measure of exercise dose and clinical outcomes. Improving the reporting of intervention characteristics and baseline exercise data in future trials would help to address this issue.

While meta-regression analyses provide a large amount of evidence based on indirect comparisons of exercise training interventions within the cardiac population, relatively few trials exist which provide direct, head-to-head comparisons of variations in individual exercise components. Our findings however are largely in agreement with this small body of literature which has found no effect of interventions with differing durations [104], frequencies $[105,106]$, session times [107] or proportions of hospitalbased sessions [108-110], on fitness, risk factors or quality of life. While avoiding the potential aggregation bias of subgroup analysis and allowing a more robust comparison of intervention characteristics, these trials are unfortunately limited by short follow-up periods and generally report only on risk factors or biological parameters, making it difficult to assess their impact on the long-term clinical outcomes observed in our analysis.

In our analysis, we did not observe higher intensity interventions to be any more effective than lower intensity ones in reducing mortality or preventing myocardial infarction in the long term. This differs to other research which suggests that increased exercise intensity is an important factor in achieving superior outcomes in patients with cardiovascular disease. Systematic reviews have shown high-intensity interval training (HIIT) to be better than moderate-intensity continuous exercise training at improving fitness $\left(\mathrm{VO}_{2}\right.$ peak) in patients with coronary heart disease [111, 112] or lifestyle-induced chronic disease [113]. Increased exercise intensity was also associated with increased gains in fitness in a recent systematic review [18] and in a large cohort of cardiac rehabilitation 
patients [114]. However, our review included only eight trials which specifically used interval training protocols, and the intensities prescribed during work intervals were generally lower than those observed in the HIIT literature. Additionally, all trials included in our analysis compared changes in clinical endpoints rather than fitness. While cardiorespiratory fitness is recognised as an important prognostic factor for mortality $[115,116]$ and is associated with decreased incidence of myocardial infarction and revascularisation in patients with CAD [117], a direct link between exercise intensity and clinical endpoints is yet to be made, as most trials are limited by short-term followup (4 months or less) and are underpowered to detect changes in clinical endpoints. One trial which did report an extended follow-up period of 4 years [118] found no difference in the rate of recurrent myocardial infarction (fatal and non-fatal) between patients randomised to low or high intensity exercise.

We did however observe evidence of a statistically significant relationship between the highest intensity of exercise prescribed to participants and an increased risk of PCI events. While we were unable to find similar reports of this phenomenon in previous research, one possible explanation may be that higher intensity exercise causes higher myocardial oxygen demands (as a result of increasing heart rate, myocardial contractility, ventricular work and blood pressure) which if not met, may elicit myocardial ischaemia not otherwise observable at lower intensities [119, 120]. If observed, these symptoms may trigger further examination and invasive intervention, given that trial participants are reviewed regularly, and that PCI (like CABG) is a physician-driven endpoint which may be prone to clinically subjective decisions [121] (an elective rather than a spontaneous event like death or infarction). Additionally, PCI (as opposed to CABG) would most likely be considered the primary method of revascularisation in this population, given that most of those enrolled in the trials would be at low subsequent cardiovascular risk [122]. It is also important to note that only three of the trials reporting PCI outcomes prescribed higher training intensities in an interval format $[75,89,95]$, and it may be that periods of intermittent recovery (as used in HIIT) are needed to mediate the potential negative effect of higher intensity exercise.

Why an increase in the risk of MI should occur with longer prescribed session times is also not clear. One previous trial in coronary patients has found exercise durations extended to $60 \mathrm{~min}$ blunted the beneficial effects on antioxidants and vasculature observed with $30 \mathrm{~min}$ of training [123]. Conversely, 40 and $60 \mathrm{~min}$ of training have been shown to be equally effective in improving exercise capacity and lipid profile [107]. We did observe some potential confounding between session frequency and session time, with longer session times associated with less frequent exercise sessions. Despite this, however, session frequency alone was not predictive of MI outcomes, and the relationship between session time and myocardial infarction remained after adjusting for the frequency of sessions. Further investigation of the impact of session time on MI outcomes may therefore be warranted.

\section{Exercise Adherence and Mortality}

Our finding of improved mortality outcomes with increased adherence to exercise training is supported by a similar observation in several cohort studies involving cardiac rehabilitation program attendees. Even when matched for prognostic factors, users of more cardiac rehabilitation sessions $(\geq 70 \%)$ were less likely to die over the subsequent 5 years than lower users [124], and program completers had a reduced risk of death and hospitalisation than non-completers [125]. Additionally, Hammill [126] observed what appeared to be a doseresponse gradient between sessions attended and the risk of myocardial infarction and mortality. Unfortunately, all these studies may have been subject to confounding if sicker participants were those who stopped attending earlier. Additionally, they were all based on adherence to the standardised US model of 36 supervised on-site sessions, meaning that outcomes observed may not necessarily be due to adherence alone, but the extra volume of training received. Given however that the results we observed in our study arose from adherence to programs of varying lengths and types and we found no effect of other training characteristics on mortality, adherence alone does appear to be an important factor.

While exercise adherence in itself may be an important driver behind reduced mortality, our findings could also be attributed to a phenomenon known as the 'healthy adherer effect' [127]. That is, those participants who complete more exercise sessions are also those who are more likely to adhere to medication regimens and perform other healthy lifestyle changes. Consequently, good exercise adherence could be considered a marker for adherence to other positive health behaviours which may also decrease the risk of mortality and clinical events. This has been previously observed by others, with increased attendance at on-site cardiac rehabilitation sessions related not only to reductions in all-cause mortality, re-admissions and major events, but also to greater improvements in clinical risk profile and secondary prevention behaviours such as medication and dietary adherence [128, 129]. Additionally, some 'clustering' of good lifestyle behaviours (diet, exercise, smoking cessation) was observed in survivors of MI, where increased adherence led to a decrease in mortality, myocardial infarction and stroke [130]. It could also be postulated however that cardiac rehabilitation programs in themselves promote 
adherence, by providing a structured learning environment which offers the frequent contact, skills training and selfefficacy enhancing care required for successful adherence [131]. Furthermore, knowledge about personal risk factors (usually provided at CR sessions) has been shown to correlate to a patient's ability to achieve treatment goals [132]. Consequently, attending an increasing number of sessions provides increased chances to gain these skills and knowledge. Despite these difficulties in separating out the effect of exercise adherence, it does appear to play a crucial role in clinical outcomes, which has important implications for program design.

\section{Implications for Practice}

There is a growing concern that cardiac rehabilitation needs to be re-engineered for the future, with a decreased reliance on traditional models of care $[29,133]$. In order to do this, it is essential to understand the interaction between program components and patient outcomes to ensure essential elements are retained. In terms of exercise prescription at least, our findings appear to align well with the current impetus to provide flexible, individualised and 'menu-based' models of care tailored to circumstances and individual patient needs $[134,135]$. While a number of the exercise training programs contained within our meta-regression were those of the traditional hospital-supervised, moderate-tovigorous intensity format, many alternate styles were also observed. All appeared equally effective in reducing mortality, and most also in reducing the risk of subsequent myocardial infarction. It may be more important therefore to design exercise programs in whichever format that may help to promote increase participant adherence, rather than being only concerned with the details of specific intervention components.

By considering alternative evidence-based models of exercise training, and offering flexible program design in order to increase ongoing adherence to exercise, programs may also attract an increased number of participants to their service. While a lack of referral is often cited as a significant barrier to the uptake of cardiac rehabilitation, other well-known barriers include issues with the program itself such as exercise training location, session availability or the frequency and duration of attendance required $[133,136]$. Knowledge that program design can be flexible, without greatly impacting on the clinical outcomes expected, may help to reassure clinicians when prescribing exercise training. Additionally, flexibility in design may overcome the resourcing issues faced by many programs in the current economic climate [137].

\section{Future Questions}

It appears obvious that structured exercise training has clear benefits over usual care, even when this includes physical activity advice, yet the question remains as to the minimal threshold of exercise intensity and volume to produce these changes. This is a pertinent fact to consider given the rise of health coaching interventions in recent years which provide exercise interventions in a format somewhere between general advice and structured exercise intervention $[138,139]$. Additionally, this review appears to support the hypothesis that the threshold for global health benefits may occur at low levels of intensity in people who are deconditioned. The minimum intensities in some included trials were lower than the aerobic intensity threshold for fitness improvements of $45 \% \mathrm{VO}_{2} \mathrm{R} / 60 \% \mathrm{HR}_{\max }$ proposed by Swain and Franklin [140], and consequently, it remains unclear at what point significant improvements in clinical outcome fail to occur.

\section{Strengths and Limitations}

Our study is strengthened by the use of a broad search strategy with no limitations imposed on language or date of publication. We also performed sensitivity analysis to examine the effects of missing data on all outcomes. Additionally, by using an exhaustive process to contact trial authors for missing intervention details, we were able to provide a more complete picture of exercise training than has ever been previously examined. Our analysis contains a wide range of interventions, allowing a comparison of varying exercise characteristics across a number of clinical outcomes.

The strength of our findings however is limited by the quality of the included trials. Due to poor reporting, many were rated at unclear risk of bias, and missing data were observed in a number of trials. Importantly, however, imputation of these missing data in sensitivity analysis did not significantly change the effect of cardiac rehabilitation on clinical outcomes. Many intervention details also remained missing, limiting the amount of data available to perform meta-regression. In particular, attempts at multivariable analysis (to account for any potential confounding due to correlated co-variates) were limited by the low number of interventions reporting all exercise co-variates of interest. It is not clear if these missing variables would have changed the outcome of the analysis.

It must also be recognised that the results of subgroup analyses and meta-regression performed in our study are subject to the challenges associated with interpreting complex interventions in such a manner. Separating the effects of all potential effect modifiers is difficult, particularly where this information may be unreported or unaccounted for. It must also be considered that these component parts alone may not be enough to explain the power of an intervention. A complex intervention such as cardiac rehabilitation may be more than the sum 
of its parts, and in reducing it down into these parts, we may lose the essence of what makes it a successful system [141]. The outcomes of such interventions may also be context-dependant, and it is not yet clear how this can be accounted for in analyses [142].

Finally, while this review contains a large number of trials from many countries, two thirds of them are more than 15 years old, and the majority of participants are still middle-aged men. Therefore, the generalisability of these findings to modern cardiac rehabilitation practice including participants of more varied aetiologies, elderly patients and women may be somewhat compromised.

\section{Conclusions}

This meta-analysis has shown that there is a place for exercise-based cardiac rehabilitation in the modern treatment of coronary heart disease, particularly where it plays a role in increasing the use of other secondary prevention therapies, many of which are currently suboptimal. There is little differential effect of variations in individual exercise training components, particularly on mortality outcomes. For this reason, it may be more important to offer programs which focus on achieving increased adherence to the exercise intervention, regardless of what format it may take.

\section{Additional file}

Additional file 1: Supplementary Material 1. (DOCX $131 \mathrm{~kb})$

\section{Acknowledgements}

The authors wish to thank Sarah Thorning (Medical Librarian, Centre for Research in Evidence-Based Practice, Bond University, QLD, Australia) for the assistance with designing search strategies for this study and Elaine Beller (Statistician, Centre for Research in Evidence-Based Practice, Bond University, Queensland, Australia) for the statistical consultation. We also kindly thank all authors of the included trials who responded to our requests for intervention descriptions or data.

\section{Funding}

This research received no specific grant from any funding agency in the public, commercial or not-for-profit sectors. BA is supported by an Australian Postgraduate Award funded by the Australian Federal Government. PG is supported by the National Health and Medical Research Council Research GNT1080042.

\section{Authors' Contributions}

BA contributed to the conception of the idea, study planning, collection, analysis and interpretation of the data and writing of the manuscript. PG contributed to the conception of the idea, study planning, interpretation of the data and critical revision of the manuscript. TH contributed to the study planning, interpretation of the data and critical revision of the manuscript. All authors read and approved the final manuscript.

\section{Competing Interests}

Bridget Abell, Paul Glasziou and Tammy Hoffmann declare no financial relationships or conflicts of interest which may have influenced the results of this research.

\section{Publisher's Note}

Springer Nature remains neutral with regard to jurisdictional claims in published maps and institutional affiliations.
Received: 4 November 2016 Accepted: 27 April 2017

Published online: 05 May 2017

\section{References}

1. Finegold JA, Asaria P, Francis DP. Mortality from ischaemic heart disease by country, region, and age: statistics from World Health Organisation and United Nations. Int J Cardiol. 2013:168:934-45.

2. Australian Institute of Health and Welfare. Australia's health 2014. Australia's health series no. 14. Cat. no. AUS 178. Canberra: AlHW; 2014.

3. Briffa TG, Hobbs MS, Tonkin A, Sanfilippo FM, Hickling S, Ridout SC, et al. Population trends of recurrent coronary heart disease event rates remain high. Circ Cardiovasc Qual Outcomes. 2011;4:107-13.

4. Kerr AJ, Broad J, Wells S, Riddell T, Jackson R. Should the first priority in cardiovascular risk management be those with prior cardiovascular disease? Heart. 2009;95:125-9.

5. Motivala A, Tamhane U, Ramanath VS, Saab F, Montgomery DG, Fang J, et al. A prior myocardial infarction: how does it affect management and outcomes in recurrent acute coronary syndromes? Clin Cardiol. 2008;31:590-6.

6. Redfern J, Hyun K, Chew DP, Astley C, Chow C, Aliprandi-Costa B, et al. Prescription of secondary prevention medications, lifestyle advice, and referral to rehabilitation among acute coronary syndrome inpatients: results from a large prospective audit in Australia and New Zealand. Heart. 2014; 100:1281-1

7. Nieuwlaat R, Schwalm J-D, Khatib R, Yusuf S. Why are we failing to implement effective therapies in cardiovascular disease? Eur Heart J. 2013; 34:1262-9.

8. Anderson L, Oldridge N, Thompson DR, Zwisler A-D, Rees K, Martin N, et al. Exercise-based cardiac rehabilitation for coronary heart disease: Cochrane systematic review and meta-analysis. J Am Coll Cardiol. 2016;67:1-12.

9. Oldridge $\mathrm{N}$. Exercise-based cardiac rehabilitation in patients with coronary heart disease: meta-analysis outcomes revisited. Future Cardiol. 2012;8:729-51.

10. Brown A, Taylor R, Noorani H, Stone J, Skidmore B. Exercise-based cardiac rehabilitation programs for coronary artery disease: a systematic clinical and economic review, Technol. Rep. no 34. Ottawa: Canadian Coordinating Office for Health Technology Assessment (CCOHTA); 2003.

11. Abell B, Glasziou P, Hoffmann T. Reporting and replicating trials of exercisebased cardiac rehabilitation: do we know what the researchers actually did? Circ Cardiovasc Qual Outcomes. 2015;8:187-94.

12. Clark AM, Hartling L, Vandermeer B, McAlister FA. Meta-analysis: secondary prevention programs for patients with coronary artery disease. Ann Intern Med. 2005:143:659-72.

13. Anderson L, Taylor RS. Cardiac rehabilitation for people with heart disease: an overview of Cochrane systematic reviews. Cochrane Database Syst Rev. 2014;12:CD011273.

14. Thompson SG, Higgins JPT. Treating individuals 4: can meta-analysis help target interventions at individuals most likely to benefit? Lancet. 2005:365:341-6.

15. Taylor RS, Brown A, Ebrahim S, Jolliffe J, Noorani H, Rees K, et al. Exercisebased rehabilitation for patients with coronary heart disease: systematic review and meta-analysis of randomized controlled trials. Am J Med. 2004; 116:682-92

16. Clark AM, Hartling L, Vandermeer B, Lissel SL, McAlister FA. Secondary prevention programmes for coronary heart disease: a meta-regression showing the merits of shorter, generalist, primary care-based interventions. Eur J Cardiovasc Prev Rehabil. 2007;14:538-46.

17. Ashor AW, Lara J, Siervo M, Celis-Morales C, Oggioni C, Jakovljevic DG, et al. Exercise modalities and endothelial function: a systematic review and dose-response meta-analysis of randomized controlled trials. Sport Med. 2015;45:279-96

18. Uddin J, Zwisler A-D, Lewinter C, Moniruzzaman M, Lund K, Tang LH, et al. Predictors of exercise capacity following exercise-based rehabilitation in patients with coronary heart disease and heart failure: a meta-regression analysis. Eur J Prev Cardiol. 2016;23:683-93.

19. Hoffmann TC, Glasziou PP, Boutron I, Milne R, Perera R, Moher D, et al. Better reporting of interventions: template for intervention description and replication (TIDieR) checklist and guide. BMJ. 2014;348:g1687.

20. Kip KE, Hollabaugh K, Marroquin OC, Williams DO. The problem with composite end points in cardiovascular studies: the story of major adverse cardiac events and percutaneous coronary intervention. J Am Coll Cardiol. 2008:51:701-7. 
21. Ferreira-González, Ignacio Montori VM, Busse JW, Schünemann, Holger J. Jaeschke R, Deveraux P, Permanyer-Miralda G, Guyatt G. Chapter 12.4: Composite end points. Users' Guid. to Med. Lit. A Man. evidence-based Clin. Pract. 3rd ed. New York: McGraw-Hill Education; 2015.

22. Higgins JPT, Altman DG, Sterne JAC (editors). Chapter 8: Assessing risk of bias in included studies. In: Higgins JPT, Green S, editors. Cochrane Handb. Syst. Rev. Interv. Version 5.1.0 (updated March 2011). The Cochrane Collaboration; 2011. p. www.handbook.cochrane.org.

23. Higgins JPT, Deeks JJ, Altman DG, (editors). Chapter 16: Special topics in statistics. In: Higgins JPT, Green S, editors. Cochrane Handb. Syst. Rev. Interv. version 5.1.0 (updated March 2011). The Cochrane Collaboration; 2011. p. www.handbook.cochrane.org.

24. AkI EA, Kahale LA, Agoritsas T, Brignardello-Petersen R, Busse JW, CarrascoLabra A, et al. Handling trial participants with missing outcome data when conducting a meta-analysis: a systematic survey of proposed approaches. Syst Rev. 2015;4:98.

25. Akl EA, Johnston BC, Alonso-Coello P, Neumann I, Ebrahim S, Briel M, et al. Addressing dichotomous data for participants excluded from trial analysis: a guide for systematic reviewers. PLoS One. 2013;8:e57132.

26. World Health Organization. Global recommendations on physical activity for health. Geneva: World Heath Organisation; 2010.

27. National Heart Foundation of Australia \& Cardiac Society of Australia and New Zealand. Reducing risk in heart disease: an expert guide to clinical practice for secondary prevention of coronary heart disease. Melbourne: National Heart Foundation of Australia; 2012

28. Janssen V, De Gucht V, Dusseldorp E, Maes S. Lifestyle modification programmes for patients with coronary heart disease: a systematic review and meta-analysis of randomized controlled trials. Eur J Prev Cardiol. 2013;20:620-40.

29. Clark AM, Redfern J, Briffa T. Cardiac rehabilitation: fit to face the future? Heart. 2014;100:355-6.

30. Weisfeldt ML, Zieman SJ. Advances in the prevention and treatment of cardiovascular disease. Health Aff. 2007;26:25-37.

31. Harbord RM, Higgins JPT. Meta-regression in Stata. Stata J. 2008;8:493-519.

32. Fletcher GF, Balady GJ, Amsterdam EA, Chaitman B, Eckel R, Fleg J, et al. Exercise standards for testing and training: a statement for healthcare professionals from the American Heart Association. Circulation. 2001;104:1694-740.

33. Norton K, Norton L, Sadgrove D. Position statement on physical activity and exercise intensity terminology. J Sci Med Sport. 2010;13:496-502.

34. Albus $C$, Theissen $P$, Hellmich $M$, Griebenow R, Wilhelm B, Aslim D, et al. Long-term effects of a multimodal behavioral intervention on myocardial perfusion - a randomized controlled trial. Int J Behav Med. 2009;16:219-26.

35. Andersen GS, Christiansen P, Madsen S, Schmidt G. Value of regular supervised physical training after acute myocardial infarction. Ugeskr Laeger. 1981;143:2952-5.

36. Aronov DM, KrasnitskiI VB, Bubnova MG, Pozdniakov IM, loseliani DG, Shchegol'kov AN, et al. Physical training at ambulatory-polyclinical stage in complex rehabilitation and secondary prevention of patients with ischemic heart disease after acute incidents. Effect on physical working capacity, hemodynamics, blood lipids, clinical course and prognosis (Russian cooperative study). Kardiologiia. 2009:49:49-56.

37. Belardinelli RB, Paolini P, Cianci GCG, Piva RPR, Solenghi MSM. The efficacy of exercise training after coronary angioplasty: the ETICA trial. Eur Heart J. 2001;22:200

38. Belardinelli R, Lacalaprice F, Cianci G, Piva R, Purcaro A. Abstract 3793: Exercise Training Intervention After Coronary Angioplasty (The ETICA Trial): ten-year followup. Am. Hear. Assoc. Sci. Sess. Orlando, Florida: Circulation; 2007;116(Suppl 16):862.

39. Bell J. A comparison of a multi-disciplinary home based cardiac rehabilitation programme with comprehensive conventional rehabilitation in post-myocardial infarction patients. (PhD Thesis) (University of London). London: University of London; 1998.

40. Bengtsson K. Rehabilitation after myocardial infarction. A controlled study. Scand J Rehabil Med. 1983;15:1-9.

41. Bertie J, King A, Reed N, Marshall AJ, Ricketts C. Benefits and weaknesses of a cardiac rehabilitation programme. J R Coll Physicians Lond. 1992;26:147-51.

42. Bethell HJ, Mullee MA. A controlled trial of community based coronary rehabilitation. Br Heart J. 1990;64:370-5.

43. Blumenthal JA, Sherwood A, Babyak MA, Watkins LL, Waugh R, Georgiades A, et al. Effects of exercise and stress management training on markers of cardiovascular risk in patients with ischemic heart disease. JAMA. 2005;293:1626-34.
44. Briffa TG, Eckermann SD, Griffiths AD, Harris PJ, Heath MR, Freedman SB, et al. Cost-effectiveness of rehabilitation after an acute coronary event: a randomised controlled trial. Med J Aust. 2005;183:450-5.

45. Byrkjeland R, Njerve IU, Anderssen S, Arnesen H, Seljeflot I, Solheim S. Effects of exercise training on $\mathrm{HbA}_{1 c}$ and $\mathrm{VO}_{2}$ peak in patients with type 2 diabetes and coronary artery disease: a randomised clinical trial. Diab Vasc Dis Res. 2015;12:325-33.

46. Carlsson R. Serum cholesterol, lifestyle, working capacity and quality of life in patients with coronary artery disease. Experiences from a hospital-based secondary prevention programme. Scand Cardiovasc J. 1998;32:1-20.

47. Carson P, Phillips R, Lloyd M, Tucker H, Neophytou M, Buch N, et al. Exercise after myocardial infarction: a controlled trial. J R Coll Physicians Lond. 1982;16:147-51.

48. DeBusk RF, Miller NH. Superko R, Dennis C a, Thomas RJ, Lew HT, et al. A case-management system for coronary risk factor modification after acute myocardial infarction. J Cardiopulm Rehabil. 1994;14:407-8.

49. Dugmore LD, Tipson RJ, Phillips MH, Flint EJ, Stentiford NH, Bone MF, et al. Changes in cardiorespiratory fitness, psychological wellbeing, quality of life, and vocational status following a 12 month cardiac exercise rehabilitation programme. Heart. 1999:81:359-66.

50. Engblom E, Ronnemaa T, Hämäläinen $H$, Kallio V, Vanttinen E, Knuts LR. Coronary heart disease risk factors before and after bypass surgery: results of a controlled trial on multifactorial rehabilitation. Eur Heart J. 1992;13:232-7.

51. Engblom E, Korpilahti K, Hämäläinen H, Rönnemaa T, Puukka P. Quality of life and return to work 5 years after coronary artery bypass surgery: long-term results of cardiac rehabilitation. J Cardiopulm Rehabil Prev. 1997;17:29-36.

52. Erdman R, Duivenvoorden $H$, Verhage F, Kazemier M, Hugenholtz P. Predictability of beneficial effects in cardiac rehabilitation: a randomized clinical trial of psychosocial variables. J Cardiopulm Rehabil. 1986;6:206-13.

53. Ferreira N., Fontes-Carvalho R, Sousa O, Silva G, Fonseca M, Sampaio F, et al. Effect of a cardiovascular rehabilitation program on exercise capacity and left ventricular diastolic function after an acute coronary syndrome: experience from a randomized, controlled study. Eur Heart J. 2010;31(suppl_1):xiv-xix.

54. Fletcher BJ, Dunbar SB, Felner JM, Jensen BE, Almon L, Cotsonis G, et al. Exercise testing and training in physically disabled men with clinical evidence of coronary artery disease. Am J Cardiol. 1994;73:170-4.

55. Fontes-Carvalho R, Azevedo Al, Sampaio F, Teixeira M, Bettencourt N, Campos $L$, et al. The effect of exercise training on diastolic and systolic function after acute myocardial infarction: a randomized study. Medicine (Baltimore). 2015;94:e1450.

56. Fridlund B, Pihlgren C, Wannestig L. A supportive-educative caring rehabilitation programme; improvements of physical health after myocardial infarction. J Clin Nurs. 1992;1:141-6.

57. Lidell $\mathrm{E}$, Fridlund $\mathrm{B}$. Long-term effects of a comprehensive rehabilitation programme after myocardial infarction. Scand J Caring Sci. 1996;10:67-74.

58. Giallauria F, Cirillo P, Lucci R, Pacileo M, De Lorenzo A, D’Agostino M, et al. Left ventricular remodelling in patients with moderate systolic dysfunction after myocardial infarction: favourable effects of exercise training and predictive role of $\mathrm{N}$-terminal pro-brain natriuretic peptide. Eur J Cardiovasc Prev Rehabil. 2008;15:113-8.

59. Håglin L, Lundström S, Kaati G, Bäckman L, Bygren LO. All-cause mortality of patients with dyslipidemia up to 19 years after a multidisciplinary lifestyle modification programme: a randomized trial. Eur J Cardiovasc Prev Rehabil. 2011;18:79-85.

60. Haskell WL, Alderman EL, Fair JM, Maron DJ, Mackey SF, Superko HR, et al. Effects of intensive multiple risk factor reduction on coronary atherosclerosis and clinical cardiac events in men and women with coronary artery disease. The Stanford Coronary Risk Intervention Project (SCRIP). Circulation. 1994;89:975-90.

61. Hofman-Bang C, Lisspers J, Nordlander R, Nygren A, Sundin O, Ohman A, et al. Two-year results of a controlled study of residential rehabilitation for patients treated with percutaneous transluminal coronary angioplasty. A randomized study of a multifactorial programme. Eur Heart J. 1999;20:1465-74.

62. Lisspers J, Sundin O, Ohman A, Hofman-Bang C, Rydén L, Nygren A. Longterm effects of lifestyle behavior change in coronary artery disease: effects on recurrent coronary events after percutaneous coronary intervention. Health Psychol. 2005;24:41-8.

63. Holmbäck AM, Sawe U, Fagher B. Training after myocardial infarction: lack of long-term effects on physical capacity and psychological variables. Arch Phys Med Rehabil. 1994;75:551-4. 
64. Kallio $\mathrm{V}$, Hämäläinen $\mathrm{H}$. Reduction in sudden deaths by a multifactorial intervention programme after acute myocardial infarction. Lancet. 1979; 314:1091-4

65. Hämäläinen $H$, Luurila $O$, Kallio V, Knuts LR. Reduction in sudden deaths and coronary mortality in myocardial infarction patients after rehabilitation. 15year follow-up study. Eur Heart J. 1995;16:1839-44.

66. Kovoor P, Lee AKY, Carrozzi F, Wiseman V, Byth K, Zecchin R, et al. Return to full normal activities including work at two weeks after acute myocardial infarction. Am J Cardiol. 2006;97:952-8.

67. KrasnitskiI VB, Sechenova EV, Bubnova MG, Aronov DM, Ioseliani DG. The use of a short program of physical training in patients with ischemic heart disease after endovascular (coronary) interventions in complex program of rehabilitation and secondary prevention at dispensary-ambulatory stage. Kardiologiia. 2010;50:27-34.

68. La Rovere MT, Bersano C, Gnemmi M, Specchia G, Schwartz PJ. Exerciseinduced increase in baroreflex sensitivity predicts improved prognosis after myocardial infarction. Circulation. 2002;106:945-9.

69. Lear SA, Singer J, Banner-Lukaris D, Horvat D, Park JE, Bates J, et al. Randomized trial of a virtual cardiac rehabilitation program delivered at a distance via the Internet. Circ Cardiovasc Qual Outcomes. 2014;7:952-9.

70. Leizorovic A. Comparison of a Rehabilitation Program, a Counseling Program and Usual Care After an Acute Myocardial-Infarction-Results of a Long-Term Randomized Trial (PRECOR Group). Eur Heart J. 1991;12:612-6.

71. Marchionni N, Fattirolli F, Fumagalli S, Oldridge N, Del Lungo F, Morosi L, et al. Improved exercise tolerance and quality of life with cardiac rehabilitation of older patients after myocardial infarction: results of a randomized, controlled trial. Circulation. 2003;107:2201-6.

72. Miller NH, Haskell WL, Berra K, DeBusk RF. Home versus group exercise training for increasing functional capacity after myocardial infarction. Circulation. 1984;70:645-9.

73. Maroto Montero JM, de Pable ZC, Morales Duran MD, Artigao RR. [Heart rehabilitation. Cost-effectiveness analysis]. Rev Esp Cardiol. 1996;49:753-8.

74. Maroto Montero JM, Artigao Ramírez R, Morales Durán MD, de Pablo ZC, Abraira V, Artigao Ramirez R, et al. Cardiac rehabilitation in patients with myocardial infarction: a 10-year follow-up study. Rev Esp Cardiol. 2005;58:1181-7.

75. Munk PS, Staal EM, Butt N, Isaksen K, Larsen Al. High-intensity interval training may reduce in-stent restenosis following percutaneous coronary intervention with stent implantation. A randomized controlled trial evaluating the relationship to endothelial function and inflammation. Am Heart J. 2009;158:734-41.

76. Mutwalli HA, Fallows SJ, Arnous AA, Zamzami MS. Randomized controlled evaluation shows the effectiveness of a home-based cardiac rehabilitation program. Saudi Med J. 2012;33:152-9.

77. Oerkild B, Frederiksen M, Hansen JF, Simonsen L, Skovgaard LT, Prescott E. Home-based cardiac rehabilitation is an attractive alternative to no cardiac rehabilitation for elderly patients with coronary heart disease: results from a randomised clinical trial. BMJ Open. 2012;2:e001820.

78. Oldridge N, Guyatt G, Jones N, Crowe J, Singer J, Feeny D, et al. Effects on quality of life with comprehensive rehabilitation after acute myocardial infarction. Am J Cardiol. 1991;67:1084-9.

79. Ornish D, Brown S, Scherwitz L, Billings JH, Armstrong WT, Ports T, et al. Can lifestyle changes reverse coronary heart disease? Lancet. 1990;336:129-33.

80. Ornish D, Scherwitz LW, Billings JH, Brown SE, Gould KL, Merritt TA, et al. Intensive lifestyle changes for reversal of coronary heart disease. JAMA. 1998;280:2001-7.

81. Reid RD, Morrin LI, Beaton $\sqcup$, Papadakis S, Kocourek J, McDonnell L, et al. Randomized trial of an internet-based computer-tailored expert system for physical activity in patients with heart disease. Eur J Prev Cardiol. 2012;19:1357-64.

82. Román O, Gutierrez M, Luksic I, Chavez E, Camuzzi A, Villalón E, et al. Cardiac rehabilitation after acute myocardial infarction. 9-year controlled follow-up study. Cardiology. 1983;70:223-31.

83. Schuler G, Hambrecht R, Schlierf G, Niebauer J, Hauer K, Neumann J, et al. Regular physical exercise and low-fat diet. Effects on progression of coronary artery disease. Circulation. 1992;86:1-11.

84. Niebauer J, Hambrecht R, Velich T, Hauer K, Marburger C, Kalberer B, et al. Attenuated progression of coronary artery disease after 6 years of multifactorial risk intervention: role of physical exercise. Circulation. 1997;96:2534-41

85. Shaw LW. Effects of a prescribed supervised exercise program on mortality and cardiovascular morbidity in patients after myocardial infarction. The National Exercise and Heart Disease Project. Am J Cardiol. 1981;48:39-46.
86. Dorn J, Naughton J, Imamura D, Trevisan M. Results of a multicenter randomized clinical trial of exercise and long-term survival in myocardial infarction patients: the National Exercise and Heart Disease Project (NEHDP). Circulation. 1999;100:1764-9.

87. Sivarajan ES, Bruce RA, Lindskog BD, Almes MJ, Belanger L, Green B. Treadmill test responses to an early exercise program after myocardial infarction: a randomized study. Circulation. 1982;65:1420-8.

88. Specchia G, De Servi S, Scire A, Assandri J, Berzuini C, Angoli L, et al. Interaction between exercise training and ejection fraction in predicting prognosis after a first myocardial infarction. Circulation. 1996;94:978-82.

89. Ståhle A, Mattsson E, Rydén L, Unden A, Nordlander R. Improved physical fitness and quality of life following training of elderly patients after acute coronary events. A 1 year follow-up randomized controlled study. Eur Heart J. 1999;20:1475-84.

90. Hage C, Mattsson E, Stahle A. Long-term effects of exercise training on physical activity level and quality of life in elderly coronary patients-a threeto six-year follow-up. Physiother Res Int. 2003;8:13-22.

91. Stern MJ, Gorman PA, Kaslow L. The group counseling v exercise therapy study. A controlled intervention with subjects following myocardial infarction. Arch Intern Med. 1983;143:1719-25.

92. Toobert DJ, Glasgow RE, Radcliffe JL. Physiologic and related behavioral outcomes from the Women's Lifestyle Heart Trial. Ann Behav Med. 2000;22:1-9.

93. Vecchio C, Cobelli F, Opasich C, Assandri J, Poggi G, Griffo R. Early functional evaluation and physical rehabilitation in patients with wide myocardial infarction [Valutazione funzionale precoce e riabilitazione fisica nei pazienti con infarto miocardico esteso]. G Ital Cardiol. 1981;11:419-29.

94. Vermeulen A, Lie K, Durrer D. Effects of cardiac rehabilitation infarction: changes in coronary long-term prognosis after myocardial risk factors and. Am Heart J. 1983;105:798-801.

95. The Vestfold Heartcare Study Group. Influence on lifestyle measures and five-year coronary risk by a comprehensive lifestyle intervention programme in patients with coronary heart disease. Eur J Cardiovasc Prev Rehabil. 2003;10:429-37.

96. Wang W, Chair SY, Thompson DR, Twinn SF. Effects of home-based rehabilitation on health-related quality of life and psychological status in Chinese patients recovering from acute myocardial infarction. Hear Lung. 2012;41:15-25.

97. West RR, Jones DA, Henderson AH. Rehabilitation after myocardial infarction trial (RAMIT): multi-centre randomised controlled trial of comprehensive cardiac rehabilitation in patients following acute myocardial infarction. Heart. 2012;98:637-44.

98. World Health Organisation. Rehabilitation and comprehensive secondary prevention after acute myocardial infarction. Report on a study. EURO Rep. Stud. Copenhagen; 1983:84:1-99.

99. Wilhelmsen L, Sanne H, Elmfeldt D, Grimby G, Tibblin G, Wedel H. A controlled trial of physical training after myocardial infarction. Effects on risk factors, nonfatal reinfarction, and death. Prev Med (Baltim). 1975;4:491-508.

100. Yu C-M, Lau C-P, Chau J, McGhee S, Kong S-L, Cheung BM-Y, et al. A short course of cardiac rehabilitation program is highly cost effective in improving long-term quality of life in patients with recent myocardial infarction or percutaneous coronary intervention. Arch Phys Med Rehabil. 2004;85:1915-22.

101. Zwisler A-DO, Soja AMB, Rasmussen S, Frederiksen M, Abadini S, Appel J, et al. Hospital-based comprehensive cardiac rehabilitation versus usual care among patients with congestive heart failure, ischemic heart disease, or high risk of ischemic heart disease: 12-month results of a randomized clinical trial. Am Heart J. 2008;155:1106-13.

102. Lawler PR, Filion KB, Eisenberg MJ. Efficacy of exercise-based cardiac rehabilitation post-myocardial infarction: a systematic review and metaanalysis of randomized controlled trials. Am Heart J. 2011;162:571-84. e2.

103. O'Connor GT, Buring JE, Yusuf S, Goldhaber SZ, Olmstead EM, Paffenbarger Jr RS, et al. An overview of randomized trials of rehabilitation with exercise after myocardial infarction. Circulation. 1989;80:234-44.

104. Hevey D, Brown A, Cahill A, Newton H, Kierns M, Horgan JH. Four-week multidisciplinary cardiac rehabilitation produces similar improvements in exercise capacity and quality of life to a 10-week program. J Cardiopulm Rehabil Prev. 2003;23:17-21.

105. Dressendorfer RH, Franklin BA, Cameron JL, Trahan KJ, Gordon S, Timmis GC. Exercise training frequency in early post-infarction cardiac rehabitation: influence on aerobic conditioning. J Cardiopulm Rehabil Prev. 1995;15:269-76 
106. Worcester MC, Hare DL, Oliver RG, Reid MA, Goble AJ. Early programmes of high and low intensity exercise and quality of life after acute myocardial infarction. BMJ. 1993;307:1244-7.

107. Hansen D, Dendale P, Berger J, Onkelinx S, Reyckers I, Hermans A, et al. Importance of exercise training session duration in the rehabilitation of coronary artery disease patients. Eur J Cardiovasc Prev Rehabil. 2008;15:453-9.

108. Kugler J, Dimsdale JE, Hartley LH, Sherwood J. Hospital supervised vs home exercise in cardiac rehabilitation: effects on aerobic fitness, anxiety, and depression. Arch Phys Med Rehabil. 1990;71:322-5.

109. LaHaye SA, Lacombe SP, Koppikar S, Lun G, Parsons TL, Hopkins-Rosseel D. High and low contact frequency cardiac rehabilitation programmes elicit similar improvements in cardiorespiratory fitness and cardiovascular risk factors. Eur J Prev Cardiol. 2014;21:1456-64.

110. Farias-Godoy A. Design, implementation and evaluation of a reduced cardiac rehabiliation program (Phd Thesis) (Simon Fraser University). Burnaby: Simon Fraser University; 2013.

111. Liou K, Ho S, Fildes J, Ooi S-Y. High intensity interval versus moderate intensity continuous training in patients with coronary artery disease: a meta-analysis of physiological and clinical parameters. Heart Lung Circ. 2016;25:166-74

112. Pattyn N, Coeckelberghs E, Buys R, Cornelissen V, Vanhees L. Aerobic interval training vs. moderate continuous training in coronary artery disease patients: a systematic review and meta-analysis. Sport Med. 2014;44:687-700.

113. Weston KS, Wisløff U, Coombes JS. High-intensity interval training in patients with lifestyle-induced cardiometabolic disease: a systematic review and meta-analysis. Br J Sports Med. 2014;48:1227-34.

114. Vanhees L, Stevens A, Schepers D, Defoor J, Rademakers F, Fagard R. Determinants of the effects of physical training and of the complications requiring resuscitation during exercise in patients with cardiovascular disease. Eur J Cardiovasc Prev Rehabil. 2004;11:304-12.

115. Myers J, Prakash M, Froelicher V, Do D, Partington S, Atwood JE. Exercise capacity and mortality among men referred for exercise testing. N Engl J Med. 2002;346:793-801.

116. Vanhees L, Fagard R, Thijs L, Staessen J, Amery A. Prognostic significance of peak exercise capacity in patients with coronary artery disease. J Am Coll Cardiol. 1994;23:358-63.

117. Hung RK, Al-Mallah MH, McEvoy JW, Whelton SP, Blumenthal RS, Nasir K, et al. Prognostic value of exercise capacity in patients with coronary artery disease: the FIT (Henry Ford Exerclse Testing) project. Mayo Clin Proc. 2014; 89:1644-54.

118. Rechnitzer PA, Cunningham DA, Andrew GM, Buck CW, Jones NL, Kavanagh T, et al. Relation of exercise to the recurrence rate of myocardial infarction in men. Ontario exercise-heart collaborative study. Am J Cardiol. 1983;51:65-9.

119. Fletcher GF, Balady G, Froelicher VF, Hartley LH, Haskell WL, Pollock ML. Exercise standards: a statement for healthcare professionals from the American Heart Association. Circulation Am Heart Assoc. 1995;91:580-615.

120. Duncker DJ, Bache RJ. Regulation of coronary blood flow during exercise. Physiol Rev. 2008;88:1009-86

121. Kazi DS, Hlatky MA. Repeat revascularization is a faulty end point for clinical trials. Circ Cardiovasc Qual Outcomes. 2012;5:249-50.

122. Windecker S, Kolh P, Alfonso F, Collet J-P, Cremer J, Falk V, et al. 2014 ESC/EACTS Guidelines on myocardial revascularization. Eur Heart J. 2014;35:2541-619.

123. Michaelides AP, Soulis D, Antoniades C, Antonopoulos AS, Miliou A, loakeimidis $\mathrm{N}$, et al. Exercise duration as a determinant of vascular function and antioxidant balance in patients with coronary artery disease. Heart. 2011;97:832-7.

124. Suaya JA, Stason WB, Ades PA, Normand S-LT, Shepard DS. Cardiac rehabilitation and survival in older coronary patients. J Am Coll Cardiol. 2009:54:25-33.

125. Martin B-J, Hauer T, Arena R, Austford LD, Galbraith PD, Lewin AM, et al. Cardiac rehabilitation attendance and outcomes in coronary artery disease patients. Circulation. 2012;126:677-87.

126. Hammill BG, Curtis LH, Schulman KA, Whellan DJ. Relationship between cardiac rehabilitation and long-term risks of death and myocardial infarction among elderly Medicare beneficiaries. Circulation Am Heart Assoc. 2010;121:63-70.

127. Simpson SH, Eurich DT, Majumdar SR, Padwal RS, Tsuyuki RT, Varney J, et al. A meta-analysis of the association between adherence to drug therapy and mortality. BMJ. 2006;333:15.

128. Alter DA, Zagorski B, Marzolini S, Forhan M, Oh PI. On-site programmatic attendance to cardiac rehabilitation and the healthy-adherer effect. Eur J Prev Cardiol. 2015;22:1232-46.
129. Doll JA, Hellkamp A, Thomas L, Ho PM, Kontos MC, Whooley MA, et al. Effectiveness of cardiac rehabilitation among older patients after acute myocardial infarction. Am Heart J. 2015;170:855-64.

130. Chow CK, Jolly S, Rao-Melacini P, Fox KAA, Anand SS, Yusuf S. Association of diet, exercise, and smoking modification with risk of early cardiovascular events after acute coronary syndromes. Circulation Am Heart Assoc. 2010; 121:750-8.

131. Burke L, Dunbar-Jacob J, Hill M. Compliance with cardiovascular disease prevention strategies: a review of the research. Ann Behav Med. 1997;19:239-63.

132. Alm-Roijer C, Fridlund B, Stagmo M, Erhardt L. Knowing your risk factors for coronary heart disease improves adherence to advice on lifestyle changes and medication. J Cardiovasc Nurs. 2006;21:24-31.

133. Balady GJ, Ades PA, Bittner VA, Franklin BA, Gordon NF, Thomas RJ, et al. Referral, enrollment, and delivery of cardiac rehabilitation/secondary prevention programs at clinical centers and beyond: a presidential advisory from the American Heart Association. Circulation. 2011;124:2951-60.

134. Redfern J, Maiorana A, Neubeck L, Clark AM, Briffa T. Achieving coordinated secondary prevention of coronary heart disease for all in need (SPAN). Int J Cardiol. 2011;146:1-3.

135. British Association for Cardiovascular Prevention and Rehabilitation. The BACPR standards and core components for cardiovascular disease prevention and rehabilitation 2012 (2nd edition). London: The British Association for Cardiovascular Prevention and Rehabilitation; 2012.

136. Daly J, Sindone AP, Thompson DR, Hancock K, Chang E, Davidson P. Barriers to participation in and adherence to cardiac rehabilitation programs: a critical literature review. Prog Cardiovasc Nurs. 2002;17:8-17.

137. Abell B, Glasziou P, Briffa T, Hoffmann T. Exercise training characteristics in cardiac rehabilitation programmes: a cross-sectional survey of Australian practice. Open Hear. 2016;3:e000374. British Cardiovascular Society.

138. Vale MJ, Jelinek MV, Best JD, Dart AM, Grigg LE, Hare DL, et al. Coaching patients On Achieving Cardiovascular Health (COACH): a multicenter randomized trial in patients with coronary heart disease. Arch Intern Med. 2003:163:2775-83.

139. Chow CK, Redfern J, Hillis GS, Thakkar J, Santo K, Hackett ML, et al. Effect of lifestyle-focused text messaging on risk factor modification in patients with coronary heart disease. JAMA. 2015;314:1255-63.

140. Swain DP, Franklin BA. Is there a threshold intensity for aerobic training in cardiac patients? Med Sci Sport Exerc. 2002;34:1071-5. 2002/07/20.

141. Hawe P, Shiell A, Riley T. Complex interventions: how "out of control" can a randomised controlled trial be? BMJ. 2004;328:1561. LP-1563.

142. Datta J, Petticrew M. Challenges to evaluating complex interventions: a content analysis of published papers. BMC Public Health. 2013;13:568. BioMed Central

\section{Submit your manuscript to a SpringerOpen ${ }^{\circ}$ journal and benefit from:}

- Convenient online submission

- Rigorous peer review

- Immediate publication on acceptance

- Open access: articles freely available online

- High visibility within the field

- Retaining the copyright to your article

Submit your next manuscript at $>$ springeropen.com 